\title{
Impacts of simulated herbivory on volatile organic compound emission profiles from coniferous plants
}

\author{
C. L. Faiola ${ }^{1, *}$, B. T. Jobson ${ }^{1}$, and T. M. VanReken ${ }^{1}$ \\ ${ }^{1}$ Laboratory for Atmospheric Research, Department of Civil and Environmental Engineering, Washington State University, \\ Pullman, Washington, USA \\ *now at: Department of Applied Physics, University of Eastern Finland, Kuopio, Finland
}

Correspondence to: T. M. VanReken (vanreken@wsu.edu)

Received: 18 July 2014 - Published in Biogeosciences Discuss.: 18 September 2014

Revised: 24 November 2014 - Accepted: 11 December 2014 - Published: 28 January 2015

\begin{abstract}
The largest global source of volatile organic compounds (VOCs) in the atmosphere is from biogenic emissions. Plant stressors associated with a changing environment can alter both the quantity and composition of the compounds that are emitted. This study investigated the effects of one global change stressor, increased herbivory, on plant emissions from five different coniferous species: bristlecone pine (Pinus aristata), blue spruce (Picea pungens), western redcedar (Thuja plicata), grand fir (Abies grandis), and Douglas-fir (Pseudotsuga menziesii). Herbivory was simulated in the laboratory via exogenous application of methyl jasmonate (MeJA), a herbivory proxy. Gas-phase species were measured continuously with a gas chromatograph coupled to a mass spectrometer and flame ionization detector (GC-MS-FID). Stress responses varied between the different plant types and even between experiments using the same set of saplings. The compounds most frequently impacted by the stress treatment were alpha-pinene, beta-pinene, 1,8cineol, beta-myrcene, terpinolene, limonene, and the cymene isomers. Individual compounds within a single experiment often exhibited a different response to the treatment from one another.
\end{abstract}

\section{Introduction}

The largest global source of volatile organic compounds (VOCs) in the atmosphere is emissions from vegetation (Guenther et al., 2000, 2012). These biogenic VOCs (BVOCs) oxidize in the atmosphere and can contribute significantly to the formation of secondary pollutants such as ozone and secondary organic aerosol (SOA) (Atkinson, 2000; Ehn et al., 2014; Hamilton et al., 2009; Kroll and Seinfeld, 2008), and thus play a key role in Earth's climate (Carslaw et al., 2010). Plants emit a wide range of organic compounds that will be classified here structurally into three categories: small oxygenated VOCs (OVOCs), terpenoids (isoprene, monoterpenes, sesquiterpenes, and their oxygenated derivatives), and aromatics (Herrmann and Weaver, 1999; Kesselmeier and Staudt, 1999). The regulation of BVOC emissions depends on both physiological and physicochemical controls that vary both between plant species and between different compounds produced within a single tree (Niinemets et al., 2004).

Some BVOCs are constitutive, meaning they are continuously synthesized and emitted by the plant while being regulated by the physiological and physicochemical mechanisms described above. Constitutive emissions can be either de novo or pooled depending on the absence or presence of storage structures. A single plant can emit both de novo and pooled emissions simultaneously (Loreto et al., 2000). In contrast to constitutive emissions, some BVOC emissions are inducible, meaning they are only synthesized and emitted when the plant is exposed to an abiotic or biotic stress that initiates their production. These stress-induced emission rates can make up a significant amount of total plant BVOC emissions (Blande et al., 2007; Brilli et al., 2009; Staudt and Lhoutellier, 2007). They also can increase or decrease the secondary organic aerosol formation potential of the BVOC emissions depending on the types of VOCs that are induced (Mentel et al., 2013). 
Plant stress can significantly alter the BVOC emission profile both by inducing emissions of additional compounds and by changing the emissions of constitutive compounds (Arneth and Niinemets, 2010). This is an important consideration because different VOCs, even within the same class of compounds, can vary by orders of magnitude in their chemical reactivity (Atkinson and Arey, 1998). A variety of stress exposure studies have been performed investigating BVOC emission changes due to ozone exposure (Heiden et al., 1999; Vuorinen et al., 2004), salt stress (Loreto and Delfine, 2000; Teuber et al., 2008), increased $\mathrm{CO}_{2}$ (Calfapietra et al., 2009; Constable et al., 1999), enhanced radiation (Harley et al., 1996), drought and/or high temperatures (Kleist et al., 2012; Niinemets, 2010; Niinemets et al., 2010), herbivory (Achotegui-Castells et al., 2013; Copolovici et al., 2011; Engelberth et al., 2004), and pathogen attack (Jansen et al., 2009a; Toome et al., 2010). A thorough review on this topic was presented by Peñuelas and Staudt (2010). Despite the numerous studies investigating this topic, most of these stress influences on BVOC emission rates are still not understood well enough to be included in the models used to develop emissions inventories (Guenther et al., 2012). This is in large part the result of two main factors: (1) the absence of enough quantitative experimental data to generate useful algorithms and (2) the large variability in stress response between trees and even between different compounds emitted by the same tree (Peñuelas and Staudt, 2010, and references therein).

Generally, a plant's response to stress depends on the longevity and severity of the stress exposure. Under mild to moderate abiotic stress, biochemical defense pathways are activated that induce and/or increase BVOC emissions, a response that protects the plant from both oxidative and thermal stress (Loreto and Schnitzler, 2010). However, the stress response changes for different types of compounds depending on the physicochemical properties of the compound. For example, emissions of small OVOCs (e.g., methanol, acetaldehyde, and acetone) are closely related to stomatal conductance whereas terpenes are not (Niinemets et al., 2004). Terpenes are hydrocarbons that can diffuse out of the plants into the atmosphere directly through the plant's membranes (Fall and Monson, 1992; Loreto et al., 1996). Consequently, stomatal conductance has no impact on the regulation of terpene emissions because of their chemical properties. In contrast, OVOCs cannot diffuse directly through plant membranes and easily dissolve in aqueous solutions, which further hinders volatilization. Thus, the effects of drought and/or heat stress impact OVOC emissions and terpene emissions differently because plants have evolved mechanisms to deal with these stressors by controlling their stomata. This stressor increases OVOC emissions in the short-term, but after prolonged exposure to the stressor, plants close their stomata to conserve water and a resulting drop in OVOC emissions occurs (Filella et al., 2007; Graus et al., 2013). This same threshold effect was not observed for terpene foliar con- centrations and terpene emissions from Mediterranean tree species and C4 crops (Blanch et al., 2009; Graus et al., 2013). However, other studies have demonstrated that under severe enough drought stress, monoterpene emissions also begin to decrease (Ormeno et al., 2007; Simpraga et al., 2011). Presumably, at some extreme, the plant shuts down metabolic activity and terpene pools, if present, are depleted.

One important stressor in future climates will be the increased number of plant-eating pests, leading to increased herbivory (Bale et al., 2002). Plants have evolved to respond to herbivory stress by emitting BVOCs as a defense, using them for communication with other plants, and to signal natural predators of the herbivores (Engelberth et al., 2004). It is well established that herbivory can increase monoterpene, sesquiterpene, and small OVOC emission rates and substantially alter the BVOC profile (Achotegui-Castells et al., 2013; Hu et al., 2008; Laothawornkitkul et al., 2008; Semiz et al., 2012). The presence of herbivore infestation can increase BVOC emissions by 4- to 20-fold (Amin et al., 2012, 2013; Berg et al., 2013), and this response can last for several weeks (Priemé et al., 2000). These results suggest that herbivore stress could have a substantial impact on SOA formation in forest environments in the future. However, the number of plants studied using quantitative analytical techniques to measure compound-specific BVOC emission rates is not representative of all the major BVOC emitters in different environments. Furthermore, within the pool of plants that have been studied, large variation has been observed in responses. Emissions of different compounds from the same plant exhibit different temporal responses to herbivory stress (Copolovici et al., 2011). Additionally, the plant stress response varies depending on the type of biotic stress and/or the type of plant; other studies have shown increases in total terpene emission rates after herbivory exposure with no change in the VOC profile (Jansen et al., 2009b; Priemé et al., 2000) or different responses of the same plant to pathogen vs. herbivory stress (Vuorinen et al., 2007). Finally, extrapolating these results to natural environments is further complicated where simultaneous exposure to multiple stressors is likely the rule rather than the exception; multiple abiotic and biotic stressors can interact to significantly alter the plant's response relative to any single stressor (Holopainen and Gershenzon, 2010; Trowbridge et al., 2014; Winter et al., 2012).

This study adds to our knowledge of climate change stress impacts on BVOC emission rates by quantitatively investigating the impacts of an herbivore treatment on the VOC profile and emission rates from five different coniferous tree species that have not been the focus of other herbivory studies. This study was a component of a project that investigated the effects of herbivory stress on the composition of biogenic SOA generated from BVOC emissions (Faiola et al., 2014b). Published data on this topic is extremely limited, so one goal of this work was to identify key tree species that could produce a large herbivore-treatment effect on SOA composition. The herbivore treatment was an exogenous application of the 
plant hormone methyl jasmonate (MeJA). MeJA is a compound that plants use in nature to warn neighboring plants about the presence of herbivores; when plants are exposed to this compound, their emissions respond in a manner similar to if they were being attacked (Martin et al., 2003). This response is not plant species specific and allows even plants of different species to communicate with one another (Farmer and Ryan, 1990). The plant species used in this study are native to temperate coniferous forests in the mountainous regions of the western United States and Canada.

Responses to the simulated herbivory stress varied between tree types. Additionally, responses also varied between experiments using the same group of trees within a single tree species, and for different compounds within the same experiment. These results reinforce the necessity to obtain quantitative, compound-specific stress response measurements on a survey of representative trees in an area before stress-induced emissions can be integrated into biogenic emissions model inventories. We also identify a list of VOCs that showed similar stress responses across experiments and could significantly affect atmospheric chemical processes in future scenarios where increased herbivory is present.

\section{Experimental approach}

This research is a component of a larger project investigating plant stress impacts on biogenic secondary organic aerosol formation, using the Washington State University's Biogenic Aerosol Formation Facility. This facility is a dual chamber system with two separate Teflon ${ }^{\circledR}$ FEP bags: one a dynamic plant emission enclosure where sapling trees are stored and the other an aerosol growth chamber. This dual chamber system uses emissions from living vegetation as a precursor VOC source for SOA generation. The objective of this paper is to present impacts of plant stress on the BVOC emission profile from the subset of experiments where continuous gas-phase measurements were available from the plant chamber. Analysis of the impacts of the stress treatment on the composition of subsequently formed SOA are presented in a separate paper (Faiola et al., 2014b).

\subsection{Tree description and treatment}

Experiments were performed with saplings from five different coniferous species: bristlecone pine (Pinus aristata), blue spruce (Picea pungens), western redcedar (Thuja plicata), grand fir (Abies grandis), and Douglas-fir (Pseudotsuga menziesii). Pinus aristata and Picea pungens are found in the Rocky Mountains of Colorado. Thuja plicata, Abies grandis, and Pseudotsuga menziesii have wider latitudinal ranges and are found in the northern Rockies of the United States and Canada as well as the western mountain ranges of North America from Alaska to California. Emphasis in the experimental design was on the diversity of representative tree species included, with the goal of identifying species that responded strongly to stress treatment in ways that might affect SOA composition. This emphasis limited the number of replications that were possible.

Saplings were 1-3 years of age at the time of the experiments, and were purchased from the University of Idaho Forestry Nursery. Plants were cared for by greenhouse staff to ensure consistent watering and fertilization. They were stored outside of the greenhouse to be closer to their natural environmental conditions and prevent unnatural plant emission behavior that could occur within greenhouse conditions. This also meant the plants could have been exposed to natural stressors (e.g., heat or herbivory). These natural stressors were not controlled but would be representative of conditions encountered by the plants in nature because it is likely that exposure to multiple stressors is the rule rather than the exception in a forest environment (Holopainen and Gershenzon, 2010). Plant specimens were transported from the greenhouse to the laboratory plant chamber at least 2 days before treatment in order to capture a baseline VOC profile. Plants required $24-36 \mathrm{~h}$ to acclimate to the plant chamber after transportation. A summary of experiments is provided in Table 1.

Treatments using MeJA or jasmonic acid have been used to simulate herbivory response in plants (Filella et al., 2006; Rodriguez-Saona et al., 2001) and can change the terpene emission profile (Martin et al., 2003). The stress treatment used in these experiments was a foliar application of $200 \mathrm{~mL}$ of $10 \mathrm{mM}$ MeJA solution in 18.2 $\mathrm{M} \Omega$ purity water, based on previously reported methods (Martin et al., 2003). Negative control experiments were performed with each tree species, but only two (one from Pinus aristata and one from Picea pungens) were performed while the GC-MS-FID was in operation. The negative control treatment was a foliar application of $200 \mathrm{~mL}$ of $18.2 \mathrm{M} \Omega$ purity water.

\subsection{Description of plant chamber and analytical instrumentation}

Three to nine individual saplings were stored in the $0.9 \mathrm{~m} \times 0.9 \mathrm{~m} \times 0.9 \mathrm{~m}$ plant enclosure for each experiment; the number depended on the size and age of the trees. The plant enclosure was equipped with a lamp (Lumatek HighPAR Output HPS Lamp, 600W) set on a $12 \mathrm{~h}$ on/off cycle to simulate the day/night cycle. Photosynthetically active radiation (PAR) was continuously monitored with an Apogee model SQ-215 quantum sensor. Temperature and relative humidity were not controlled but were continuously monitored with a Vaisala model HMP110 humidity and temperature probe. The plant enclosure was continuously purged with zero air at 9.5 standard $\mathrm{L} \mathrm{min}^{-1}$ (Aadco model 737 pure air generator).

Gas-phase emissions from the saplings were continuously monitored with a gas chromatograph coupled to a mass spectrometer and flame ionization detector (Agilent model 
Table 1. Experiment Summary.

\begin{tabular}{|c|c|c|c|c|c|c|}
\hline Plant scientific name & Common name & Experiment ID & Experiment type & Measurement dates & Treatment day and time & SOA generation experiments* \\
\hline Picea pungens & Blue spruce & PP-E1 & MeJA & 12-17 May & 15 May 11:40 & PPu-1-Post \\
\hline Picea pungens & Blue spruce & PP-C & Negative control & 8-15 July & 11 July 15:00 & none \\
\hline Picea pungens & Blue spruce & PP-E2 & MeJA & 15-19 July & 17 July $10: 40$ & $\mathrm{PPu}$-2-Pre, $\mathrm{PPu}$-2-Post \\
\hline Pinus aristata & Bristlecone pine & PA-E & MeJA & 19-24 May & 22 May 11:30 & PA-3-Pre, PA-3-Post \\
\hline Pinus aristata & Bristlecone pine & $\mathrm{PA}-\mathrm{C}$ & Negative control & 26-31 May & 29 May 11:00 & PA-4-Pre \\
\hline Abies grandis & Grand fir & AG-E & MeJA & 23-28 June & 26 June $11: 30$ & AG-1-Pre, AG-1-Post \\
\hline Thuja plicata & Western redcedar & TP-E & MeJA & 16-23 September & 22 September 08:30 & TP-3-Pre1, TP-3-Pre2, TP-3-Post \\
\hline Pseudotsuga menziesii & Douglas-fir & PM-E & MeJA & 23-30 September & 26 September 09:00 & PM-2-Pre, PM-2-Post \\
\hline
\end{tabular}

6890/5973 GC-MS-FID, DB-5MS column) with a time resolution of $\sim 70 \mathrm{~min}$. This instrument was equipped with a custom-built pre-concentration system described previously by Faiola et al. (2012, 2014a). The pre-concentration unit traps analytes on the Tenax ${ }^{\odot}$ GR adsorbent and uses thermodesorption to inject compounds into the GC system. The FID is essentially a "carbon counter", meaning that the current produced from the detector is a function of the number of carbons in the molecule. Consequently, if the structure of the molecule is known, the concentration may be quantified using the effective carbon number concept with an upper-limit instrumental error of $\pm 10 \%$ (Faiola et al., 2012). Identifications of the following compounds could be made based on retention times determined using commercial standards: 3-carene, terpinolene, limonene, alphapinene, beta-pinene, alpha-terpinene, beta-myrcene, and $o$ cymene. Molecular structures of other peaks were determined by interpreting the mass spectra acquired with the MS detector along with retention indices for monoterpenes. Integrated peak areas from the FID were converted to emission rates using Eq. (1):

$E=\frac{A_{\mathrm{a}} \chi_{\mathrm{s}} N_{\mathrm{s}} M_{\mathrm{a}} F}{1000 A_{\mathrm{s}} N_{\mathrm{a}} B}$.

Here, $E$ is the emission rate normalized to plant biomass in units of $\mu \mathrm{g}-\mathrm{C} \mathrm{g}^{-1} \mathrm{~h}^{-1}, A_{\mathrm{a}}$ and $A_{\mathrm{s}}$ are the integrated FID peak areas of the analyte and internal standard, respectively, $\chi_{\mathrm{s}}$ is the mixing ratio of the internal standard (ppbV), $N_{\mathrm{a}}$ and $N_{\mathrm{s}}$ are the effective carbon numbers of the analyte and internal standard, respectively, $M_{\mathrm{a}}$ is the analyte molar mass of carbon $\left(\mathrm{g}-\mathrm{C} \mathrm{mol}^{-1}\right), F$ is the molar flow through the plant enclosure $\left(\right.$ mol-air $\left.\mathrm{h}^{-1}\right), 1000$ is a conversion factor to obtain the appropriate units, and $B$ is the biomass of needles in the plant enclosure (g). Effective carbon numbers were estimated using the effective carbon number concept (Faiola et al., 2012; Sternberg et al., 1962). Biomass was estimated by collecting and weighing a subset of needles from each tree after they were removed from the plant chamber. Needles were dried for a minimum of $24 \mathrm{~h}$ in an oven before weighing; furthermore, dry needle weight was scaled up to the tree level by estimating the number of needles on each tree.

The GC-MS-FID used in this study was optimized to quantify monoterpenes. It can also quantitatively analyze aromatic emissions of a similar size. These emissions are dependent on temperature and were temperature normalized to $303 \mathrm{~K}$ using Eq. (2) (Guenther et al., 1993):

$E(T)=E_{\mathrm{S}} * e^{\left(\beta\left(T-T_{\mathrm{S}}\right)\right)}$,

where $E(T)$ is the measured emission rate at a measured temperature $(T)$, and $E_{\mathrm{S}}$ is the standardized basal emission rate (BER) at standard temperature $\left(T_{\mathrm{S}}\right)$. The activity adjustment factor, $\beta\left(\mathrm{K}^{-1}\right)$, was calculated for each experiment using measured emission rates between the post-acclimation period and treatment application. The number of points varied from experiment to experiment, but included a minimum of $24 \mathrm{~h}$ of measurements. Activity adjustment factors were calculated for terpenes and terpenoid aromatics separately because their chemical structures are slightly different and thus their chemical properties are expected to also differ. Results of these calculations are summarized in Table 2 . The activity adjustment factors calculated here ranged from 0.15 to $0.59 \mathrm{~K}^{-1}$, with most values ranging from 0.15 to $0.26 \mathrm{~K}^{-1}$. Where a relationship between temperature and emission rate was observed and an activity adjustment factor could be calculated, nearly all values calculated for the terpenes were consistent with the ranges previously reported for coniferous tree species by Helmig et al. (2013) and Ortega et al. (2008) $\left(0.08\right.$ to $\left.0.28 \mathrm{~K}^{-1}\right)\left(0.00\right.$ to $\left.0.23 \mathrm{~K}^{-1}\right)$. The one exception was the activity adjustment factor calculated for Pseudotsuga menziesii, which was much higher than any of the others, but which also had the highest temperature/emission rate (ER) correlation observed from any experiment $\left(r^{2}=0.91\right.$ for monoterpenes and $r^{2}=0.89$ for aromatics). No aromatic compounds were observed above detection limit during the pre-treatment period for experiment PP-E1, so no activity adjustment factor could be calculated. Additionally, there was no relationship between temperature and emission rate during the pre-treatment period for the Abies grandis experiment. In this case, the average activity adjustment factor from the other experiments was used to temperature normalize the emissions for the Abies grandis experiment (excluding the apparent outlier from Pseudotsuga menziesii).

In addition to monoterpenoids, this analytical system could detect and identify isoprene and some small OVOCs. However, these compounds had low breakthrough volumes for the Tenax ${ }^{\odot}$ adsorbent used, and so they were not quanti- 
Table 2. Summary of activity adjustment factors for total monoterpenes and total aromatics that were calculated from pre-treatment emissions. Dashes indicate that no relationship could be established between temperature and emission rate for that experiment.

\begin{tabular}{lrrrrr}
\hline Experiment ID & MT $\beta\left(\mathrm{K}^{-1}\right)$ & $r^{2}$ & Aromatic $\beta\left(\mathrm{K}^{-1}\right)$ & $r^{2}$ & Temperature range (K) \\
\hline PP-E1 & 0.21 & 0.87 & - & - & $293-300$ \\
PP-E2 & 0.17 & 0.82 & 0.21 & 0.76 & $298-305$ \\
PA-E & 0.19 & 0.72 & 0.25 & 0.69 & $292-301$ \\
AG-E & - & - & - & - & - \\
TP-E & 0.15 & 0.86 & 0.26 & 0.79 & $297-302$ \\
PM-E & 0.52 & 0.91 & 0.59 & 0.89 & $297-301$ \\
\hline
\end{tabular}

tatively captured on the adsorbent trap. Thus, absolute emission rates are not reported for those compounds. Instead, the relative measured value could be analyzed to look at trends in changing emissions from day to day. Where used, these emissions were normalized to their maximum measured emission rate and presented as a unitless value.

\subsection{Calculating atmospheric reactivity of BVOC emissions}

One potential impact of stress-induced changes in the monoterpenoid profile is on the oxidative reactivity of the BVOC emissions. To evaluate this, it is necessary to isolate the impact of the changing terpenoid profile on reactivity and exclude any impacts from changes to absolute emission rates. To do this, the sum total monoterpenoid mixing ratio was normalized to $1 \mathrm{ppbV}$ and the mixing ratio of each individual monoterpenoid was calculated from the relative terpenoid contribution. This reactivity will be referred to as the concentration-normalized reactivity of the BVOC emission profile. The total mixing ratio value of $1 \mathrm{ppbV}$ was selected as a reasonable approximation of summertime afternoon monoterpene mixing ratios in the canopy of a forest environment (Bryan et al., 2012; Nölscher et al., 2012). The compounds used in the reactivity calculations and their corresponding $\mathrm{OH}$ and $\mathrm{O}_{3}$ rate constants are presented in Table 3. Reaction rate constants were obtained from experimental results in the literature where available (Atkinson et al., 1990; Calvert et al., 2000; Corchnoy and Atkinson, 1990; Gai et al., 2013; Reissell et al., 2001; United States Environmental Protection Agency, 2014) or were calculated using the method described in Calvert et al. (2000). Ring strain was ignored for the ozone reaction rate constants. Concentration-normalized $\mathrm{OH}$ and $\mathrm{O}_{3}$ reactivity of plant $\mathrm{BVOC}$ emission profiles were calculated from the sum of the individual BVOC reactivities, which were calculated as the product of the reaction rate constant and the normalized mixing ratio. The resulting total $\mathrm{OH}$ and $\mathrm{O}_{3}$ reactivity is the inverse of the $\mathrm{OH}$ and $\mathrm{O}_{3}$ lifetime. Only those compounds listed in Table 3 were included in the calculation. This list includes all the major VOCs that were identified in these experiments.
Table 3. Reaction rate constants for monoterpenoids at $298 \pm 2 \mathrm{~K}$ Units are $\mathrm{cm}^{3}$ molecule $\mathrm{s}^{-1}$.

\begin{tabular}{lrr}
\hline Compound & $\mathrm{OH}$ rate constant & $\mathrm{O}_{3}$ rate constant \\
\hline santene & $1.10 \times 10^{-10}$ & $1.10 \times 10^{-15}$ \\
2-bornene & $5.64 \times 10^{-11}$ & $1.20 \times 10^{-16}$ \\
alpha-thujene & $8.69 \times 10^{-11}$ & $4.00 \times 10^{-16}$ \\
alpha-pinene & $5.37 \times 10^{-11}$ & $8.66 \times 10^{-17}$ \\
alpha-fenchene & $5.14 \times 10^{-11}$ & $1.10 \times 10^{-17}$ \\
camphene & $5.33 \times 10^{-11}$ & $9.00 \times 10^{-19}$ \\
2,4-thujadiene & $1.08 \times 10^{-10}$ & $1.31 \times 10^{-16}$ \\
beta-terpinene & $1.44 \times 10^{-10}$ & $4.42 \times 10^{-16}$ \\
beta-myrcene & $2.15 \times 10^{-10}$ & $4.70 \times 10^{-16}$ \\
alpha-phellandrene & $3.13 \times 10^{-10}$ & $3.00 \times 10^{-15}$ \\
3-carene & $8.80 \times 10^{-11}$ & $3.70 \times 10^{-17}$ \\
alpha-terpinene & $3.63 \times 10^{-10}$ & $2.10 \times 10^{-14}$ \\
limonene & $1.70 \times 10^{-10}$ & $2.00 \times 10^{-16}$ \\
beta-phellandrene & $1.68 \times 10^{-10}$ & $4.70 \times 10^{-17}$ \\
1,8-cineol & $1.11 \times 10^{-11}$ & $1.50 \times 10^{-19}$ \\
beta-ocimene & $2.52 \times 10^{-10}$ & $5.40 \times 10^{-16}$ \\
gamma-terpinene & $1.77 \times 10^{-10}$ & $1.40 \times 10^{-16}$ \\
terpinolene & $2.25 \times 10^{-10}$ & $1.90 \times 10^{-15}$ \\
$m$-cymene & $1.51 \times 10^{-11}$ & $5.00 \times 10^{-20}$ \\
$p$-cymene & $1.51 \times 10^{-11}$ & $5.00 \times 10^{-20}$ \\
$o$-cymene & $1.51 \times 10^{-11}$ & $5.00 \times 10^{-20}$ \\
$o$-cymenene & $6.65 \times 10^{-11}$ & $5.00 \times 10^{-20}$ \\
$p$-cymenene & $6.65 \times 10^{-11}$ & $5.00 \times 10^{-20}$ \\
2-carene & $8.00 \times 10^{-11}$ & $2.30 \times 10^{-16}$ \\
$p$-allylanisole & $5.20 \times 10^{-11}$ & $1.03 \times 10^{-17}$ \\
camphor & $4.60 \times 10^{-12}$ & $7.00 \times 10^{-20}$ \\
beta-pinene & $7.89 \times 10^{-11}$ & $1.50 \times 10^{-17}$ \\
\hline Refrces & & \\
\hline
\end{tabular}

References used to determine these reaction rate constants were Atkinson et al. 1990; Calvert et al., 2000; Corchnoy and Atkinson, 1990; Gai et al., 2013; Reissell et al., 2001; United States Environmental Protection Agency, 2014.

\section{Results and discussion}

In this section, pre-treatment BVOC profiles from each experiment are presented first and compared with previous reports of BVOC measurements from the same tree species. This was done to investigate whether the pre-treatment BVOC profiles were representative of trees in a natural set- 
ting. Then, the stress response from each tree type is described separately, including changes to the daily average monoterpenoid profiles and temporal trends in absolute emission rates. A summary of the main compounds that were affected by the stress treatment from each tree is presented. Finally, the concentration-normalized $\mathrm{OH}$ and $\mathrm{O}_{3}$ reactivity are presented to investigate the impact of changing the BVOC profile before and after stress treatment.

\subsection{Pre-treatment monoterpene profiles}

Monoterpenoids were the dominant biogenic emissions that were quantitatively measured from each tree type in this study. These compounds have been the focus of numerous field measurements using the same species used in these experiments. Figure 1 summarizes the pre-treatment monoterpene profile for each experiment in this study. Values are presented as the percent of total monoterpenoid emission rates for each experiment. The same results are provided in absolute emission rates in Table 4. The profiles were calculated using all data from the end of the acclimation period until immediately before the stress treatment was applied. This time period varied from experiment to experiment but always included a minimum of $24 \mathrm{~h}$ of measurements. In total, 32 monoterpenoid chemical species were observed prior to treatment, including two oxygenated monoterpenes, camphor, and 1,8-cineol. Minor constituents were summed for inclusion in the profile. This group includes the following compounds: santene, 2-bornene, alpha-fenchene, 2,4-thujadiene, beta-terpinene, 2-carene, alpha-phellandrene, alpha-terpinene, gamma-terpinene, alpha-thujene, the aromatic cymenene isomers, acetophenone, two unidentified monoterpenes, and four unidentified aromatic compounds. Together, this category accounted for $<10 \%$ of all pretreatment monoterpenoid emissions. Toluene was also measured during some experiments but was not a major component and was not included in this analysis.

The pre-treatment monoterpene profile varied between the tree species (Fig. 1). However, despite differences in their distribution, the same seven compounds made up greater than $75 \%$ of all monoterpene emissions from all trees: alphapinene, limonene, 3-carene, beta-pinene, beta-myrcene, camphene, and beta-phellandrene. For the two sets of Picea pungens experiments, the pre-treatment profiles were substantially different, even though the same four saplings were used in each of the three experiments. Picea pungens emissions in May (PP-E1) were dominated by alpha-pinene and limonene, while in July (PP-E2 and PP-C) they were dominated by limonene and beta-myrcene. Each of these profiles were consistent with previous measurements made in a field setting. The Picea pungens monoterpene profile presented by Helmig et al. (2013) had higher contributions from alpha-pinene in spring, but decreased in August and September in a manner similar to what we observed in July. Furthermore, we observed an increase in the contribution of

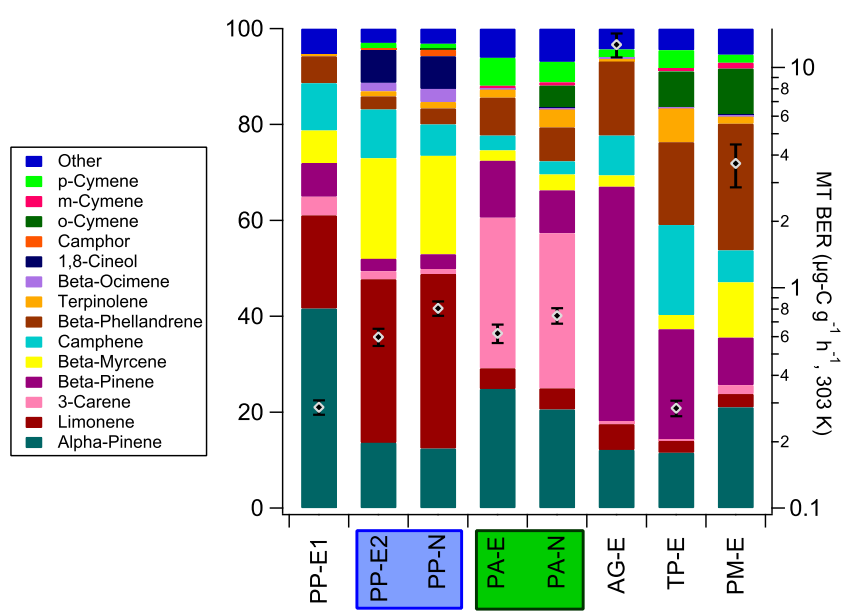

Figure 1. Pre-treatment monoterpenoid profiles for each experiment. PP-E1 represents Picea pungens stress experiment 1, PP-E2 is Picea pungens stress experiment 2, PP-N is Picea pungens negative control, PA-E is Pinus aristata stress experiment, PA-N is Pinus aristata negative control, AG-E is Abies grandis stress experiment, and PM-E is Pseudotsuga menziesii stress experiment. The two shaded boxes denote the paired stress/negative control experiments that were performed consecutively with the same set of saplings. The left axis shows the proportion of each compound emitted as a percent of total monoterpenoids. The diamonds associated with the right axis show the average pre-treatment basal emission rate (BER) of total monoterpenes normalized to a temperature of $303 \mathrm{~K}$ in units of $\mu \mathrm{g}-\mathrm{Cg}^{-1} \mathrm{~h}^{-1}$. The $x$ axis label is the experiment ID (Table 1). The average BER was calculating using all data from the end of the acclimation period until immediately before the stress treatment was applied ( $>24 \mathrm{~h}$ of measurements). The error bars represent the standard deviation of the averaged value.

1,8-cineol in the July experiments vs. the May experiment, which Helmig et al. (2013) also described. The Picea pungens monoterpenoid BER in this study ranged from 0.29 to $0.81 \mu \mathrm{g}-\mathrm{Cg}^{-1} \mathrm{~h}^{-1}\left(0.32-0.92 \mu \mathrm{g} \mathrm{g}{ }^{-1} \mathrm{~h}^{-1}\right)$. Previous reports ranged from $<0.10$ to $1.45 \mu \mathrm{g} \mathrm{g}^{-1} \mathrm{~h}^{-1}$ throughout the year, and during the months of May-July (the time period when our experiments were performed) the reported BER range was $0.87-1.45 \mu \mathrm{g} \mathrm{g}^{-1} \mathrm{~h}^{-1}$ (Helmig et al., 2013). Thus, the Picea pungens BER in our experiments was on the lower end of what has been reported from Picea pungens in the field.

The monoterpenoid profile of the Rocky Mountain bristlecone pine (Pinus aristata) has not been previously reported to our knowledge. A profile of the Great Basin bristlecone pine (Pinus longaeva) was presented by Helmig et al. (2013), and is used here for comparison. Both profiles were dominated by 3-carene, alpha-pinene, and beta-pinene. Within this study, the two Pinus aristata experiments exhibited nearly identical pre-treatment monoterpene emission profiles. These measurements were taken within 2 weeks of one another. The Pinus aristata monoterpenoid BER was $0.62-0.75 \mu \mathrm{g}-$ $\mathrm{Cg}^{-1} \mathrm{~h}^{-1}\left(0.70-0.85 \mu \mathrm{g} \mathrm{g}^{-1} \mathrm{~h}^{-1}\right)$, which is on the higher 
Table 4. Summary of the temperature-normalized pre-treatment emission rates for the dominant compound emissions. Units are emission rates in $\mu \mathrm{g}-\mathrm{C} \mathrm{g}^{-1} \mathrm{~h}^{-1}$ normalized to $303 \mathrm{~K}$. A dash indicates the compound was not detected and $b d l$ indicates the compound was detected but it was below the calculated detection limit for quantification (detection limit $=0.003 \mu \mathrm{g}-\mathrm{Cg}^{-1} \mathrm{~h}^{-1}$ ). The average sum basal emission rate (BER) is provided at the bottom of the table for each experiment; $\sigma$ denotes the standard deviation of the measurements used to calculate the pre-treatment average.

\begin{tabular}{lrrrrrrrr}
\hline & PP-E1 & PP-E2 & PP-N & PA-E & PA-N & AG-E & TP-E & PM-E \\
\hline alpha-pinene & 0.119 & 0.081 & 0.100 & 0.154 & 0.153 & 1.537 & 0.033 & 0.769 \\
limonene & 0.056 & 0.204 & 0.293 & 0.027 & 0.033 & 0.682 & 0.007 & 0.102 \\
3-carene & 0.011 & 0.010 & 0.008 & 0.195 & 0.242 & 0.076 & bdl & 0.067 \\
beta-pinene & 0.020 & 0.015 & 0.025 & 0.074 & 0.067 & 6.203 & 0.066 & 0.363 \\
beta-myrcene & 0.020 & 0.125 & 0.165 & 0.014 & 0.025 & 0.297 & 0.008 & 0.422 \\
camphene & 0.028 & 0.061 & 0.053 & 0.019 & 0.021 & 1.054 & 0.053 & 0.244 \\
beta-phellandrene & 0.016 & 0.016 & 0.027 & 0.049 & 0.053 & 1.958 & 0.049 & 0.968 \\
terpinolene & - & 0.006 & 0.011 & 0.010 & 0.028 & 0.074 & 0.020 & 0.054 \\
beta-ocimene & - & 0.011 & 0.022 & - & bdl & - & - & 0.008 \\
1,8-cineol & - & 0.041 & 0.055 & - & - & - & - & - \\
camphor & - & bdl & 0.011 & - & - & - & - & - \\
$o$-cymene & - & - & - & - & 0.036 & - & 0.022 & 0.358 \\
$m$-cymene & - & - & - & 0.005 & 0.005 & - & 0.002 & 0.045 \\
$p$-cymene & bdl & 0.008 & 0.010 & 0.036 & 0.032 & 0.247 & 0.011 & 0.062 \\
other & 0.016 & 0.018 & 0.026 & 0.038 & 0.052 & 0.548 & 0.013 & 0.199 \\
sum BER & 0.286 & 0.597 & 0.806 & 0.621 & 0.746 & 12.675 & 0.284 & 3.661 \\
$\sigma$ & 0.022 & 0.054 & 0.061 & 0.060 & 0.060 & 1.576 & 0.023 & 0.807 \\
\hline
\end{tabular}

end of the range of Pinus longaeva BER values reported by Helmig et al. (2013) in May and June, 0.16-0.74 $\mu \mathrm{g} \mathrm{g}^{-1} \mathrm{~h}^{-1}$.

The Abies grandis, Pseudotsuga menziesii, and Thuja plicata monoterpene profiles each differed from what has been reported previously. The profile from Abies grandis in this study was dominated by beta-pinene, but no beta-pinene was observed by Ortega et al. (2008). This difference could be explained by natural genotypic variation because Ortega et al. (2008) also observed natural variation in the constitutive BVOC profiles between plants of the same tree species. However, the Abies grandis monoterpenoid pre-treatment BER measured in our experiment was $12.67 \mu \mathrm{g}-\mathrm{C} \mathrm{g}^{-1} \mathrm{~h}^{-1}$, substantially higher than any other pre-treatment monoterpenoid BER observed in this study and more than an order of magnitude greater than that reported by Ortega et al. (2008) for the same tree species. These high emission rates could suggest the Abies grandis saplings were likely exhibiting a stress response prior to treatment.

For Pseudotsuga menziesii, the dominant monoterpene emission measured in this study was beta-phellandrene (40\% of all monoterpenoid emissions). Helmig et al. (2013) observed alpha-pinene and beta-pinene comprising more than $50 \%$ of all Pseudotsuga menziesii monoterpenoid emissions throughout an entire year of measurements, which was consistent with the profile presented in Geron et al. (2000). However, Ortega et al. (2008) observed variability in Pseudotsuga menziesii monoterpene profiles in the field, reporting that limonene and camphene were the dominant emissions during one set of measurements, while sabinene and alphapinene were for another. Furthermore, beta-pinene emissions were measured for one reported BVOC profile by Ortega et al. (2008) but not for the other. Thus, the pre-treatment profile in this laboratory study could still be representative of a natural baseline condition. The pre-treatment $\mathrm{Pseu}$ dotsuga menziesii BER measured in our laboratory chamber was $3.66 \mu \mathrm{g}-\mathrm{Cg} \mathrm{g}^{-1} \mathrm{~h}^{-1}$. This was the second-highest observed BER value prior to treatment, and is consistent with previous reports where values as high as $3.40 \mu \mathrm{g}-\mathrm{Cg}^{-1} \mathrm{~h}^{-1}$ were measured from Pseudotsuga menziesii branch enclosures by Ortega et al. (2008). However, our laboratory experiment was conducted in September when seasonal reports of emissions have shown decreasing emission trends. For example, the highest BER reported in the field by Helmig et al. (2013) was $2.51 \mu \mathrm{g}-\mathrm{C} \mathrm{g}^{-1} \mathrm{~h}^{-1}$ in June, but they reported that by September the monoterpenoid BER had dropped back down to $0.12 \mu \mathrm{g}-\mathrm{Cg}^{-1} \mathrm{~h}^{-1}$. Thus, the BERs in our experiment were at the upper range of what would be expected in the natural environment from Pseudotsuga menziesii at this time of year.

Thuja plicata monoterpenoid emissions in this study were dominated by beta-pinene, camphene, and betaphellandrene, whereas Ortega et al. (2008) found that $61 \%$ of all monoterpenoid emissions were composed of the oxygenated compounds alpha- and beta-thujone. We did not observe any thujone emissions throughout the measurement period. The monoterpenoid pre-treatment BER from Thuja plicata was the lowest we observed from any species at $0.28 \mu \mathrm{g}$ $\mathrm{Cg}^{-1} \mathrm{~h}^{-1}$. This was consistent with the Thuja plicata BER reported by Ortega et al. (2008), $0.30 \mu \mathrm{g}-\mathrm{Cg}^{-1} \mathrm{~h}^{-1}$. 


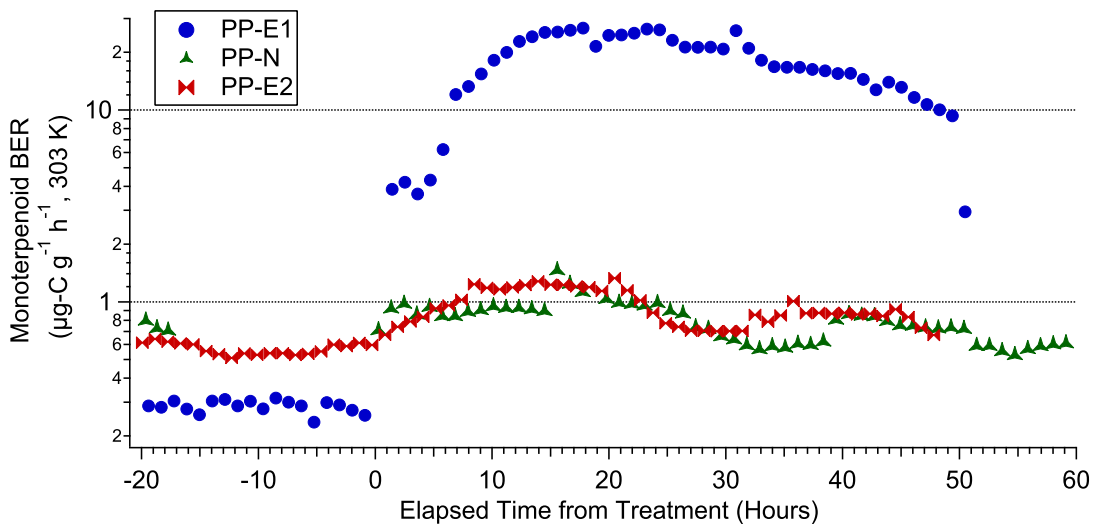

Figure 2. A summary of monoterpenoid emissions from all three Picea pungens experiment. The only experiment to exhibit a clear stress effect on monoterpenoid emission rates following treatment was the first methyl jasmonate (MeJA) experiment performed in May (PP-E1).

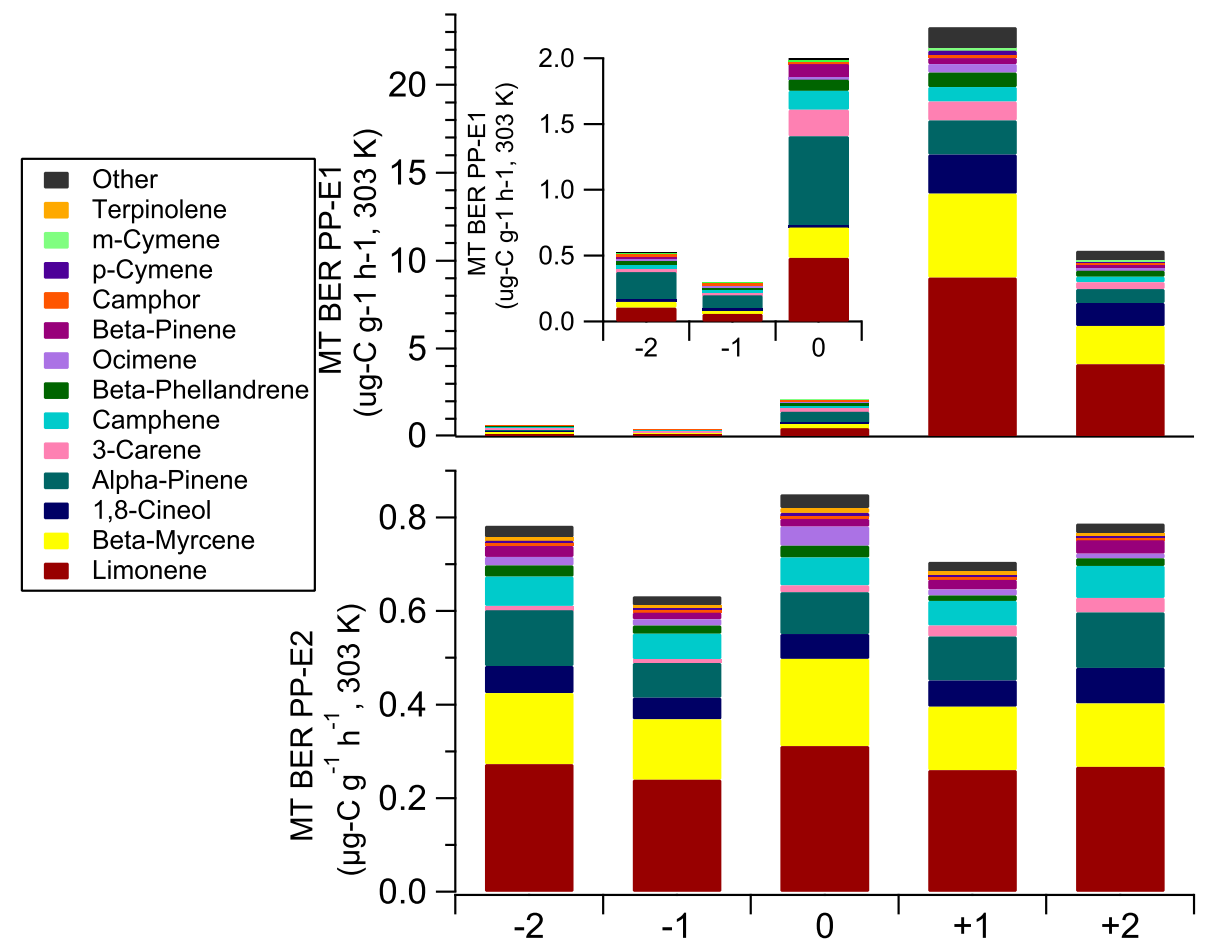

Figure 3. Summary of monoterpenoid profile for the two Picea pungens methyl jasmonate (MeJA) experiments. The $x$ axis denotes the day relative to treatment, where treatment was performed on day 0 . The $y$ axis is the monoterpenoid (MT) basal emission rate normalized to $303 \mathrm{~K}$. Results from the methyl jasmonate (MeJA) experiment performed in May are presented in the top plot and the results from the MeJA experiment performed in July are presented in the bottom plot. Note the difference in $y$ axis scale for the top plot vs. the bottom plot. The inset in the top plot is provided as an enlargement of the profiles for days $-2,-1$, and 0 for experiment PP-E1.

\subsection{Blue spruce (Picea pungens)}

Three experiments were performed using Picea pungens saplings, two with MeJA treatments and one negative control. All three experiments were performed using the same four saplings, and the negative control experiment was performed the week prior to the July MeJA-treatment experiment. The two MeJA-treatment experiments did not produce consistent results. To illustrate this, a plot of the total monoterpenoid BER vs. elapsed time since treatment is shown in Fig. 2. The first treatment experiment performed in May exhibited a clear stress response where monoterpene emissions increased from $0.29 \pm 0.2$ to $23.27 \pm 2.15 \mu \mathrm{g}-\mathrm{Cg}^{-1} \mathrm{~h}^{-1}$. This represents an 80-fold increase after treatment. Emissions remained elevated above pre-treatment values over the next $50 \mathrm{~h}$. In stark contrast, the monoterpene emissions from the 
July MeJA experiment did not demonstrate a significantly different response to stress than did the negative control. There was a small increase in emissions for both PP-N and PP-E2 on the day of treatment. The short lived, slight emissions increase observed in these experiments could possibly be the result of an abiotic surface adsorption disruption effect; water displaces organic molecules previously adsorbed to the needle surfaces and produces a burst in measured emissions. This phenomenon has been observed in a natural forest environment where bursts of VOC emission were observed following rain (in a natural forest setting) or water application (in a laboratory setting) (Faiola et al., 2014a; Greenberg et al., 2012; Warneke et al., 1999). This would suggest that there was no significant stress treatment effect and that the small increase in some emissions observed on the treatment day could be a function of the treatment method itself rather than an actual stress response.

The difference in these results was also apparent when the complete BVOC profiles were examined (Fig. 3). These values are the average daytime emissions (6:00 to 18:00 LT). To simplify the presentation, BVOCs that individually constituted less than $1 \%$ of all monoterpenoid emissions were summed and presented in the "Other" category. The pretreatment aromatic emissions for the PP-E1 experiment were too low to calculate an aromatic activity adjustment factor, so the activity adjustment factor for aromatics calculated from PP-E2 data was used to normalize aromatic emission rates for both experiments.

In PP-E1, the maximum stress response for all classes of compounds was observed the day after treatment $($ day +1$)$. The highest-emitted monoterpene before treatment was alpha-pinene (>40\% of all MT emissions, Fig. 1). After treatment, limonene, beta-myrcene, and 1,8-cineol dominated the emission profile. Limonene and beta-myrcene were constitutive emissions that were stimulated more than other constitutive emissions after treatment. In addition to enhancing constitutive emissions, the stress treatment also induced many new monoterpenoid emissions, including alphaphellandrene, alpha-terpinene, 1,8-cineol, ocimene, gammaterpinene, and terpinolene. Some of these induced compounds did not contribute significantly to the overall posttreatment emissions and were thus lumped into the other category, but they are worth noting because they were only observed after treatment had been applied. Specifically, 1,8cineol and ocimene were emitted at rates well over 2 orders of magnitude higher than the detection limit after treatment, i.e., above the 80 -fold increase in total emissions, which suggests these emissions were truly induced and not just emitted at rates below the detection limit prior to treatment. Negligible amounts of aromatic compounds were observed before treatment. After treatment, even though aromatics still made up a small relative proportion of overall emissions, the aromatic emissions (predominantly $p$-cymene) increased significantly to $0.5 \mu \mathrm{g}-\mathrm{Cg}^{-1} \mathrm{~h}^{-1}$, which was similar to the pre-treatment sum monoterpenoid BERs for many of the tree species presented in Fig. 1. Emissions of all classes of compounds began to decrease again within $48 \mathrm{~h}$ after treatment, but still remained elevated relative to pre-treatment values when measurements ceased.

In contrast to the May experiment, in the July Picea pungens experiment the monoterpenoid average profile did not significantly change after treatment (Fig. 3). This could be due to seasonal differences in the sensitivity of Picea pungens to herbivore treatment. This has been observed in other coniferous plant species. For example, monoterpene synthesis in Pinus sylvestris is more responsive to plant stressors during the spring when shoots are actively growing (Bäck et al., 2005). In the Picea pungens experiment presented here, there were small increases in terpinolene and ocimene emissions on the day of treatment, but they quickly returned to pre-treatment levels. Furthermore, results from the May experiment suggested that 1,8-cineol was a stress-induced compound that was only observed after treatment, but this same compound constituted a significant proportion of the pretreatment BVOC emission profile in the July experiment. This could be a natural seasonal effect; field measurements have demonstrated seasonal changes in 1,8-cineol emission rates from Picea pungens (Helmig et al., 2013). However, it is also possible that the 1,8 -cineol emission rate fluctuations observed in the field were due to the presence of some natural stressor. Thus, the pre-treatment profile for the July experiment could indicate that the trees' metabolic stress pathways had been activated prior to experimental treatment. This hypothesis is further supported by the higher percentage of beta-myrcene and limonene emissions present in the July pre-treatment profile that more closely resemble the posttreatment stress profile from the May experiment. This combined with the low emission rate values could suggest that the trees had been exposed to an external stressor for an adequate length of time to cause the plant to begin shutting down metabolic processes. If this was the case, the application of an additional stress treatment did not produce a stress response under those conditions.

Averaging emission rates over each day provides a clean picture of the overall VOC profiles, but any patterned variability that may occur through the day would be hidden by this approach. Another way to investigate changing VOC profiles is to compare the emission rate data for different compounds to evaluate their covariance. If paired compounds co-vary, then their relative emissions are consistent over time. If their correlation is weaker, it suggests that the profile is changing, possibly due to differences in the factors regulating the compounds' emissions.

Constitutive emissions co-varied throughout the negative control experiment (PP-N). Emission rates of beta-myrcene, alpha-pinene, and beta-phellandrene were plotted against limonene emissions and shown in Fig. 4. Limonene was used as the basis for comparison because it was the dominant constitutively emitted compound (Fig. 1). Measurements from the first $36 \mathrm{~h}$ while the plants were acclimat- 


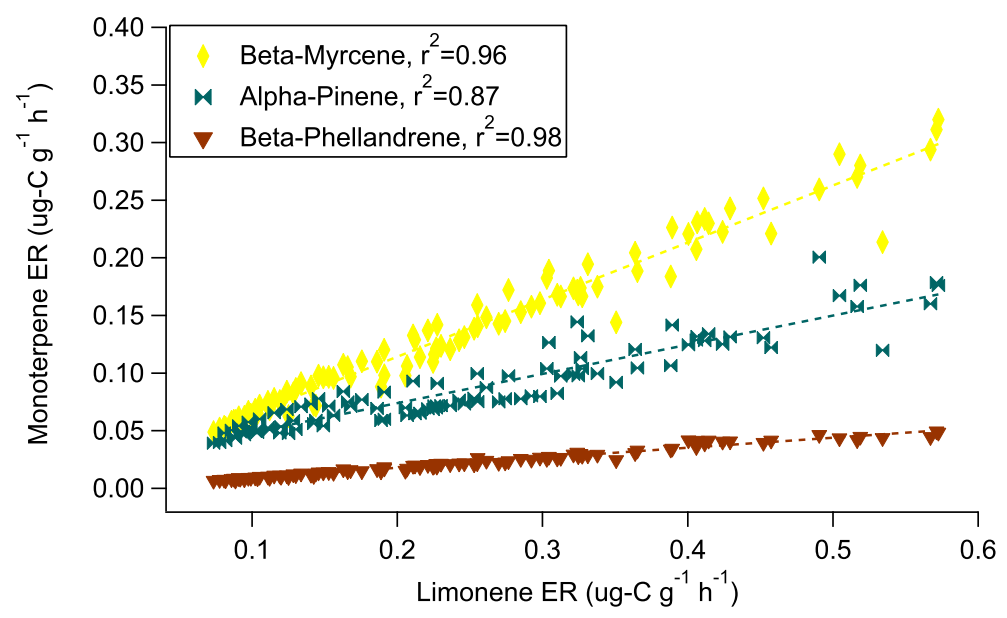

Figure 4. Covariance of constitutively emitted monoterpenes during the Picea pungens negative control experiment performed in July (PPN).

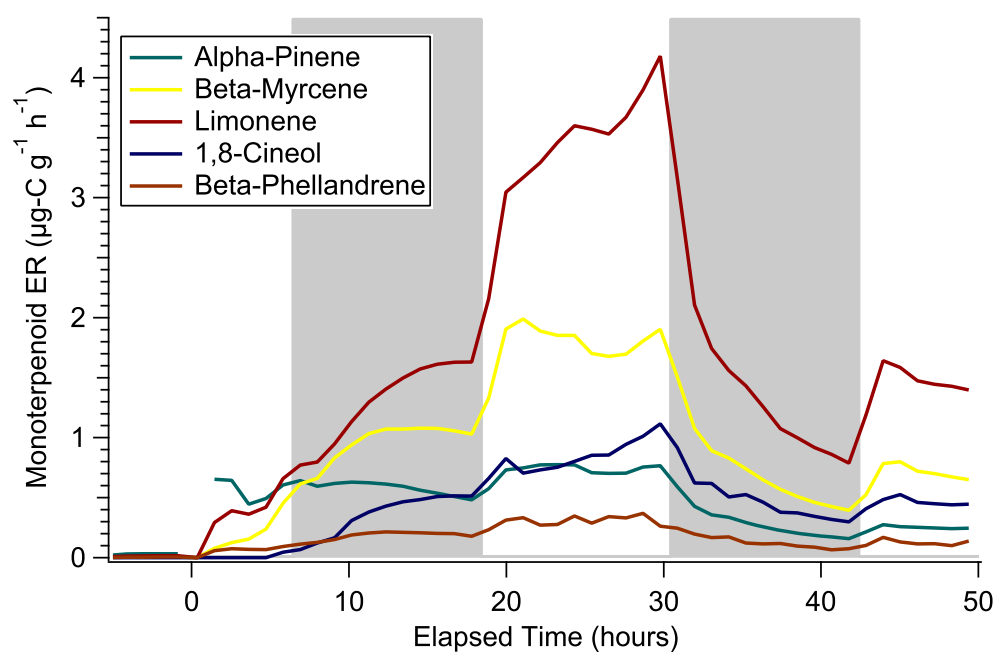

Figure 5. Post-treatment emission rates for five monoterpenoid species during the PP-E1 experiment. The $x$ axis denotes the elapsed time since treatment application in hours. Alternating shaded and unshaded regions demonstrate when the light above the plant enclosure was turned off and on, respectively.

ing to the plant chamber were excluded from the analysis. Correlations between these three constitutively emitted compounds and limonene were high with $r^{2}$ values ranging from 0.87 to 0.98 . This was also true for the other compounds' emissions, with emission rate correlation coefficients with limonene ranging between 0.85 and 0.96 . Camphor was the exception; the correlation between camphor and limonene emissions was 0.35 .

In the May MeJA experiment (PP-E1), the dominant pretreatment constitutive emission was alpha-pinene but after treatment, the major emissions were limonene, betamyrcene, and 1,8-cineol (Fig. 3). For this experiment, it was informative to look at both the time series of emission rates as well as the covariance between emission rates of difference compounds. A time series of the emission rates after treatment for a subset of the compounds is shown in Fig. 5. Immediately after treatment on 15 May, 2013 at 11:40 LT, alpha-pinene was still the dominant terpene emitted. However, emissions of limonene and beta-myrcene began to increase quickly and had exceeded alpha-pinene emissions by later that evening. Emissions of 1,8-cineol did not begin to increase until 17:00 LT. After that, they continued to increase and surpassed alpha-pinene emissions early the following morning. Beta-phellandrene is also shown on the figure to provide an example of a less dominant emission trend. It immediately began to increase after treatment but never exceeded alpha-pinene emissions. The emission trends of betamyrcene, limonene, 1,8-cineol, and beta-phellandrene are in contrast to the trend in alpha-pinene emission rates. Alphapinene was not impacted by the treatment and maintained a 
stable emission rate throughout the evening while emission rates of other compounds steadily increased.

The covariance of emission rates after treatment was analyzed by investigating correlations with alpha-pinene (the dominant pre-treatment constitutive emission) and limonene (the dominant post-treatment emission). The correlation between post-treatment emissions of limonene, beta-myrcene, 1,8-cineol, and alpha-pinene were low with $r^{2}$ values ranging from 0.13 to 0.45 . Emission rates of alpha-pinene were only well-correlated with two compounds, camphene $\left(r^{2}=0.77\right)$ and beta-pinene $\left(r^{2}=0.97\right)$. For all other compounds the $r^{2}$ ranged between 0.04 and 0.61 . Post-treatment correlations between beta-myrcene, 1,8-cineol, and beta-phellandrene and the most stress-enhanced compound, limonene, ranged from 0.85 to 0.90 . Limonene emission were also well correlated with ocimene $\left(r^{2}=0.89\right), p$-cymene $\left(r^{2}=0.83\right)$, and terpinolene $\left(r^{2}=0.90\right)$. This could suggest that the MeJA treatment induced de novo emissions of limonene, betamyrcene, beta-phellandrene, 1,8-cineol, ocimene, $p$-cymene, and terpinolene. After the emissions were induced, these compounds exhibited similar emission patterns because of similar enzymatic controls on de novo production. 3-Carene and $m$-cymene emissions were not well correlated with either alpha-pinene or limonene emissions.

\subsection{Western redcedar (Thuja plicata)}

The VOC daily profiles for the Thuja plicata MeJA experiment are summarized in Fig. 6. For this experiment, nine small saplings were kept in the plant chamber for 6 days before applying treatment, and were removed from the chamber the day after treatment. However, for this group of plants there was an exceptionally strong emission response that continued to increase throughout the night following treatment. Consequently, day $+1 / 2$ has been included on the chart to capture peak emission response, and refers to the nighttime period that occurred half a day after treatment application. The pre-treatment and post-treatment profiles were plotted separately due to the drastic increase in the emission rate; monoterpene BER increased from an average value of $0.28 \pm 0.02 \mu \mathrm{g}-\mathrm{Cg}^{-1} \mathrm{~h}^{-1}$ on days -6 to -4 to a maximum average value of $11.88 \pm 0.18 \mu \mathrm{g}-\mathrm{Cg}^{-1} \mathrm{~h}^{-1}$ during the evening after treatment. This is a 42 -fold increase in monoterpenoid BER. Terpinolene, beta-myrcene, and the cymene isomers increased most substantially and dominated the monoterpene profile after treatment.

The post-treatment temporal emissions trends for the Thuja plicata experiment exhibited a pattern that was not observed for other trees species. Figure 7 shows the monoterpenoid BER time series immediately following treatment. In Fig. 7, the treatment was applied on 22 September at 08:30 LT, and emissions of all compounds began to increase by 13:00 LT the same day. The emissions of nearly all compounds continued to rise or stabilized at an elevated emission rate for the remainder of the measurement period until

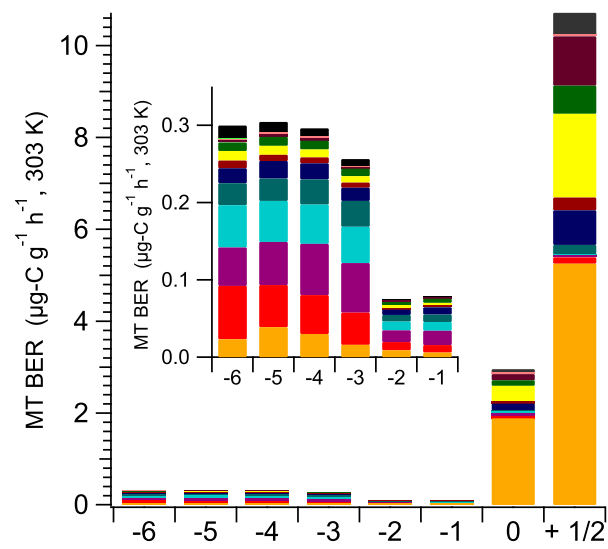

Figure 6. Emission profile of emissions from Thuja plicata during methyl jasmonate (MeJA) experiment TP-E. The $x$ axis denotes the day relative to treatment application. The $y$ axis shows the monoterpenoid BER normalized to $303 \mathrm{~K}$. Note the drastic scale change between the pre- and post-treatment $y$ axes. The insert shows an enlarged view of the first 6 days to allow better visualization of the pre-treatment period.

Table 5. Results of linear regression correlation analysis $\left(r^{2}\right)$ between all monoterpenoid emission rates (ERs) vs. terpinolene emission rates and limonene emission rates during experiment TP-E.

\begin{tabular}{lrr}
\hline & vs. Terpinolene & vs. Limonene \\
& ERs & ERs \\
\hline ocimene & 0.86 & 0.26 \\
beta-myrcene & 0.48 & 0.98 \\
$p$-cymene & 0.79 & 0.93 \\
$m$-cymene & 0.54 & 0.99 \\
$o$-cymene & 0.58 & 0.98 \\
limonene & 0.56 & - \\
alpha-thujene & 0.45 & 0.98 \\
alpha-pinene & 0.26 & 0.90 \\
gamma-terpinene & 0.80 & 0.93 \\
alpha-phellandrene & 0.42 & 0.98 \\
camphene & 0.37 & 0.92 \\
3-carene & 0.57 & 0.97 \\
beta-phellandrene & 0.88 & 0.83 \\
beta-pinene & 0.08 & 0.59 \\
\hline
\end{tabular}

23 September at 05:00 LT when measurements were stopped. However, beta-pinene did not follow this trend; instead, betapinene emissions immediately increased after treatment, but began to decrease a few hours later, starting at 15:00 LT on the treatment day. It was the only compound to exhibit this emission pattern.

Terpinolene also demonstrated a slightly different emission pattern from most other monoterpenes. This is evident from the linear regression results presented in Table 5. Terpinolene reached a maximum emission rate on the evening of the treatment day at 20:30 LT (Fig. 7). Afterwards it began to decrease slowly. The only other compound to exhibit 

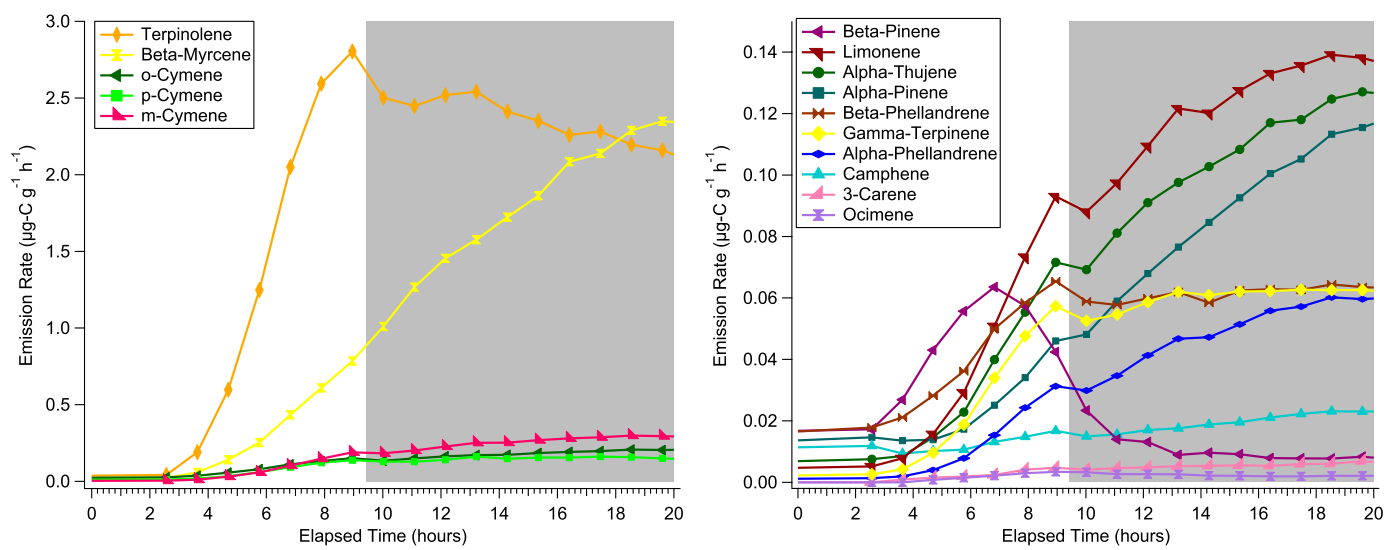

Figure 7. Time series of monoterpene emission rates from Thuja plicata. The $x$ axis shows the elapsed time since treatment application in hours. Alternating shaded and unshaded regions demonstrate when the light above the plant enclosure was turned off and on, respectively.
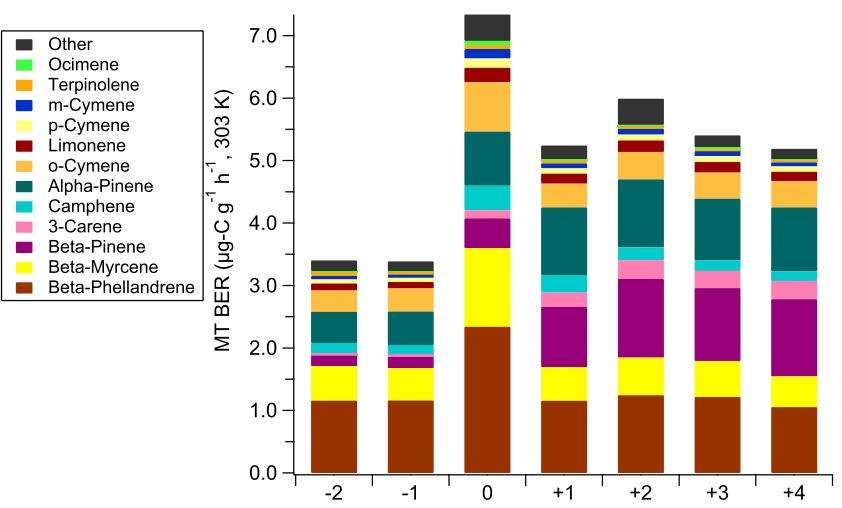

Figure 8. Douglas-fir VOC profile. The $x$ axis denotes the day relative to treatment application. The $y$ axis is the monoterpenoid basal emission rate normalized to $303 \mathrm{~K}$.

this emission trend was ocimene, which had a linear regression correlation with terpinolene emissions of 0.86. Most other compounds continued to increase throughout the night. Thus, most compound emission rates were highly correlated with limonene emissions, which exhibited this continually increasing emission trend. Ten compounds were highly correlated with limonene emissions with $r^{2}>0.90$ (Table 5). Beta-phellandrene and gamma-terpinene were well correlated with both limonene and terpinolene with $r^{2} \geq 0.80$. Their emission rates stabilized more quickly than most other compounds during the night. They were best correlated with one another with an $r^{2}=0.96$. This could suggest four different types of emission responses (1) quick increase followed by a slow decrease within $10 \mathrm{~h}$ of treatment similar to terpinolene, (2) quick increase followed by a rapid decrease similar to beta-pinene, (3) long-term increase throughout the night similar to limonene, and (4) an increase followed by stabilization within $\sim 12 \mathrm{~h}$ of treatment similar to beta-phellandrene.
Monoterpenoid BER values for Thuja plicata were the lowest pre-treatment emissions that were measured from all trees in this study. After treatment had been applied, monoterpenoid BERs increased to the third-highest emission rates measured throughout the experiments. This suggests that stress exposure in natural environments could turn normally low-emitting trees into high emitters that could contribute substantially to the net ecosystem BVOC flux. This should be considered in future experimental designs, where it may be tempting to limit tree species representation to only the known highest BVOC emitters in a region because there may be some tree species that are only high emitters under stressed conditions.

\subsection{Douglas-fir (Pseudotsuga menziesii)}

The daily average VOC emission profile from Pseudotsuga menziesii is shown in Fig. 8. Some of the minor constituents $(<1 \%$ of BER) have been grouped together within the "Other" category to simplify the presentation. For this experiment, 2 days of measurements were collected prior to treatment after plants had acclimated to the chamber. Following treatment, BVOC emission rates were monitored for another 4 days. Absolute monoterpenoid BERs approximately doubled on the day of treatment. They increased from $3.66 \pm 0.88$ to $7.34 \pm 1.04 \mu \mathrm{g}-\mathrm{C} \mathrm{g}^{-1} \mathrm{~h}^{-1}$. Emissions then remained $34 \%$ higher, on average, than baseline emissions for the following 4 days. Aromatics (predominantly $o$-cymene) comprised more than $10 \%$ of the total Pseudotsuga menziesii VOC emissions even before treatment, and thus could be significant contributors to SOA formation in natural forest environments. Emissions of alphapinene, beta-pinene, and 3-carene increased most after treatment relative to the other constitutive monoterpenes. Alphapinene emissions increased by $\sim 100 \%$, beta-pinene emissions by $\sim 570 \%$, and 3-carene emissions by $\sim 640 \%$. This effect was sustained until measurements ceased 4 days after 
treatment. One of these stress-enhanced compounds, betapinene, co-varied with the dominant constitutive emission, beta-phellandrene, prior to treatment $\left(r^{2}=0.89\right)$, but was de-coupled from beta-phellandrene emissions after treatment $\left(r^{2}=0.48\right)$. However, nearly all other compounds continued to co-vary with beta-phellandrene emissions from day +1 to day +4 after treatment. Emissions from beta-myrcene, the cymene isomers, alpha-pinene, limonene, ocimene, and terpinolene all had linear regression results of $r^{2}>0.90 \mathrm{vs}$. betaphellandrene. 3-Carene emissions did not co-vary with any other compound emissions.

The overall stress response exhibited by Pseudotsuga menziesii was not as dramatic as the 80-fold increase observed during experiment PP-E1 or the 42-fold increase observed during experiment TP-E. There was also no single stressenhanced compound that completely dominated the posttreatment emission profile as terpinolene did during experiment TP-E. Despite all this, the three most stress-enhanced compounds (alpha-pinene, beta-pinene, and 3-carene) did contribute significantly to the overall BVOC emissions during this experiment, which were substantial. Pre-treatment, the monoterpenoid BERs for Pseudotsuga menziesii were the second-highest pre-treatment values measured in this study (Fig. 1), with a daytime average pre-treatment monoterpenoid BER of $3.39 \pm 0.01 \mu \mathrm{g}-\mathrm{Cg}^{-1} \mathrm{~h}^{-1}$. The daytime average post-treatment BER was $5.46 \pm 0.37 \mu \mathrm{g}-\mathrm{Cg}^{-1} \mathrm{~h}^{-1}$. This is only a modest increase in overall emission rates relative to some of the other experiments. However, of the $2.06 \mu \mathrm{g}-\mathrm{Cg}^{-1} \mathrm{~h}^{-1}$ total increase in BER, $1.75 \mu \mathrm{g}-\mathrm{Cg}^{-1} \mathrm{~h}^{-1}$ was due to the increase in just the three most stress-enhanced compounds: alpha-pinene, beta-pinene, and 3-carene $(85 \%$ of the total increase). The post-treatment average BER of these three compounds was $2.48 \pm 0.15 \mu \mathrm{g}-\mathrm{Cg}^{-1} \mathrm{~h}^{-1}, 73 \%$ of the total monoterpenoid pre-treatment BER. Thus, these stimulated monoterpenes can significantly contribute to total BVOC emissions. This is important because different monoterpenes have widely varying chemical reactivity and SOA formation potential (Atkinson and Arey, 1998; Griffin et al., 1999).

\subsection{Grand fir (Abies grandis)}

As shown in Fig. 1, the pre-treatment monoterpene BER for the grand fir experiment was greater than for any other experiment, and was much greater than what had been previously reported elsewhere. This suggests that these trees had been exposed to some unknown external stress while being stored outdoors prior to use. To investigate this, we examined the entire BVOC profile throughout the measurement period (Fig. 9). All monoterpenoid emissions steadily decreased from day -2 to day 0 . It is possible that the trees were still acclimating to the plant chamber on day -2 , but they should have been well acclimated by day -1 because trees take $12-36 \mathrm{~h}$ to acclimate to the plant chamber (having been transported to the chamber on day -3 ). The observed

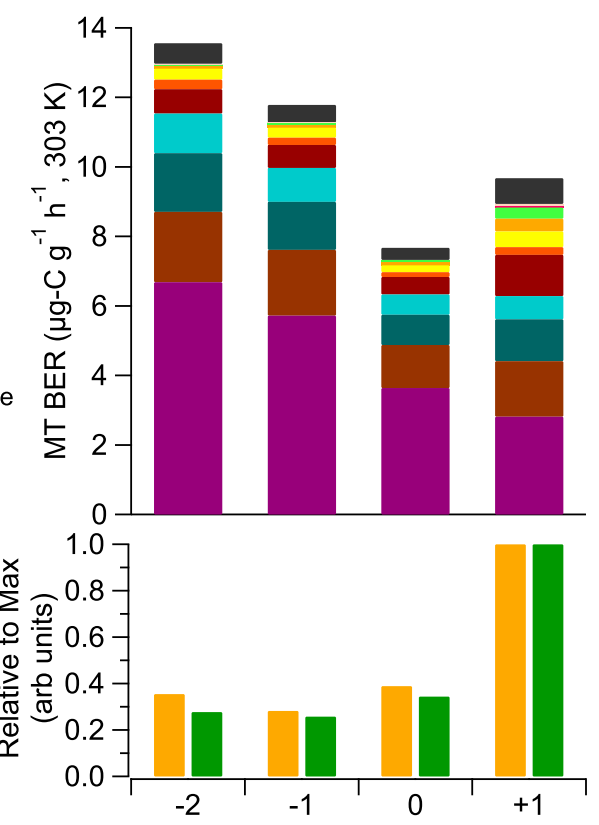

Figure 9. Grand fir BVOC profile. The $x$ axis denotes the day relative to treatment application. The top panel summarizes the monoterpenoid emissions where the $y$ axis is the monoterpenoid basal emission rate normalized to $303 \mathrm{~K}$. The bottom panel summarizes the emissions of small oxy-VOCs and other unidentified compounds where the $y$ axis is the fraction of the emission rate relative to the maximum measured value.

steady decrease from day to day could be indicative of the hypothesized unknown stress effect waning once the trees were brought into the laboratory. Laboratory notes on tree appearance for this experiment indicate that the trees had a number of dry, orange-red needles when they were transported on 23 June 2013. Another note from 28 June 2013 described large clumps of needles dropping from the trees at the slightest touch during watering. The trees were kept well watered at the greenhouse and in the laboratory chamber and outdoor temperatures were normal for the area, so we do not believe that the needle damage was the consequence of drought or temperature stress. However, this possibility cannot be ruled out completely. Alternatively, the observed effects may have been the result of an unseen herbivore or pathogen that was not detected prior to the experiment.

Despite the possible presence of an uncontrolled stressor, the experimental MeJA stress treatment did still have a small effect on BVOC emission rates and profile (Fig. 9). This effect was not immediate; emissions continued their decreasing trend on day 0 , but then increased slightly on day +1 . The BVOC profile was altered both by the induction of emissions of new compounds and by the alteration of the distribution of constitutive emissions. 1,8-Cineol and, to a much lesser extent, $p$-allylanisole were induced. The former is an oxygenated monoterpene and the latter is a phenylpropanoid produced from the shikhimic acid pathway (Dudareva et 
al., 2006). These emissions were not observed until $6 \mathrm{~h}$ after treatment for 1,8 -cineol and $22 \mathrm{~h}$ after treatment for $p$ allylanisole. Small OVOCs and unidentified compounds exhibited maximum emissions the day following stress treatment and may also have been induced by the stress treatment. Similar to the other stress-induced and stress-enhanced compounds, they exhibited a delayed response in emissions. These small OVOCs include alcohols, ketones, and aldehydes that have less than eight carbon atoms including small 5carbon to 6-carbon OVOCs produced from the lipoxygenase biochemical pathway (Connor et al., 2008; Maffei, 2010).

The constitutive monoterpene emission profile also changed. For the first 3 days, the terpene profile was dominated by beta-pinene, beta-phellandrene, and alpha-pinene, and their relative contribution to total emissions did not vary significantly. After the MeJA treatment, beta-pinene emissions continued to decrease as they had been for the previous 3 days, but limonene, beta-myrcene, beta-phellandrene, terpinolene, and alpha-pinene all increased. Increases in these compounds were observed $6 \mathrm{~h}$ after treatment, similar to when the induced compound, 1,8-cineol, was first observed. Prior to treatment, constitutive emissions of alpha-pinene, limonene, and terpinolene all co-varied with the dominant constitutive emission, beta-pinene, with all $r^{2}$ values greater than 0.90 (Fig. 10, left). Two separate bursts in emissions occurred $24 \mathrm{~h}$ apart from one another that produced the threehighest points on the plots (two measurements during one burst and one measurement during the other burst). With those points removed, alpha-pinene and limonene were still well correlated with beta-pinene with $r^{2}$ values of 0.97 and 0.89 , respectively. The terpinolene $r^{2}$ reduced to 0.52 when the two emission bursts were excluded. Other major constitutive emissions also co-varied with beta-pinene prior to treatment but were not shown in the figure; camphene, betaphellandrene, $p$-cymene, and beta-myrcene also co-varied with beta-pinene prior to treatment with $r^{2}$ values ranging from 0.94 to 0.99 . However, after treatment, beta-pinene no longer co-varied with alpha-pinene, limonene, or terpinolene with $r^{2}$ values of $0.53,0.25$, and 0.12 , respectively (Fig. 10, right). Thus, even with the emission bursts removed pre-treatment, all $r^{2}$ values decreased relative to the posttreatment correlations. Furthermore, all of the other most highly enhanced constitutive compounds except for betaphellandrene were well correlated with limonene after treatment with $r^{2}$ values $>0.80$ (not shown). The MeJA stress treatment de-coupled the dominant constitutive emissions from beta-pinene, which was not enhanced by the stress, while most of the compounds enhanced by the treatment continued to co-vary. 1,8-Cineol, the induced emission, was not well correlated with the most enhanced constitutive emission, limonene $\left(r^{2}=0.18\right)$.

\subsection{Bristlecone pine (Pinus aristata)}

A time series of the summed monoterpenoid BERs are presented in Fig. 11. There was a large spike in emissions immediately following the MeJA treatment where monoterpenoid emissions increased from 0.54 to $12.52 \mu \mathrm{g}-\mathrm{Cg}^{-1} \mathrm{~h}^{-1}$. The negative control experiment also demonstrated a slight increase in emissions, but to a much lesser extent than the MeJA experiment; monoterpenoid emissions increased from 0.81 to $2.68 \mu \mathrm{g}-\mathrm{C} \mathrm{g}^{-1} \mathrm{~h}^{-1}$. The emissions increase was short lived for both experiments and the emissions trend started to reverse within just a few hours following treatment.

The monoterpene profiles for the days before (day -1$)$ and after $($ day +1$)$ treatment are shown in Fig. 12. The total emissions were slightly reduced for the MeJA experiment on the day following treatment, but not substantially so, and the monoterpenoid profile did not change. The negative control BER and emission profile were similar before and after spraying the trees with water.

Major monoterpene emissions were plotted against the emission rates of the dominant monoterpene throughout these experiments, 3-carene, in Fig. 13. Both the negative control and MeJA experiment demonstrated high correlations $\left(r^{2}>0.9\right)$ for all monoterpene emissions relative to 3-carene. Beta-pinene, beta-phellandrene, and terpinolene are shown in the figure for illustration, and this was also true for alphapinene, $o$-cymene, $p$-cymene, limonene, camphene, betamyrcene, and $m$-cymene. This indicates that the monoterpene profile did not change substantially during either experiment.

\subsection{Summary of emission rate changes}

A summary of the change in emission rates after stress treatment for some of the key compounds is summarized for each experiment where a plant stress response was observed (Fig. 14). Note the difference in the $y$ axis scale for each experiment because the overall change in emission rates varied between plant types. For the Thuja plicata experiment, the delta value was calculated from the day $+1 / 2$ post-treatment value minus the baseline daily average from day -4 to day -6 . This is a conservative estimate of emissions changes because all emissions decreased during the 2 days prior to treatment (days -1 and -2 ) but these lower emission values were not used in the calculation. For the Picea pungens experiment, the delta BER was calculated by subtracting the average daily value on day -1 from day +1 . The maximum response was observed on day +1 and day -2 was excluded because the plants may have still been acclimating to the chamber. For the Pseudotsuga menziesii experiments, the delta BER was calculated by subtracting the average daily values on day -2 and day -1 from the average daily values on days +1 to +4 . For the Abies grandis experiment, the delta BER was calculated as the difference between day 0 and day +1 . 

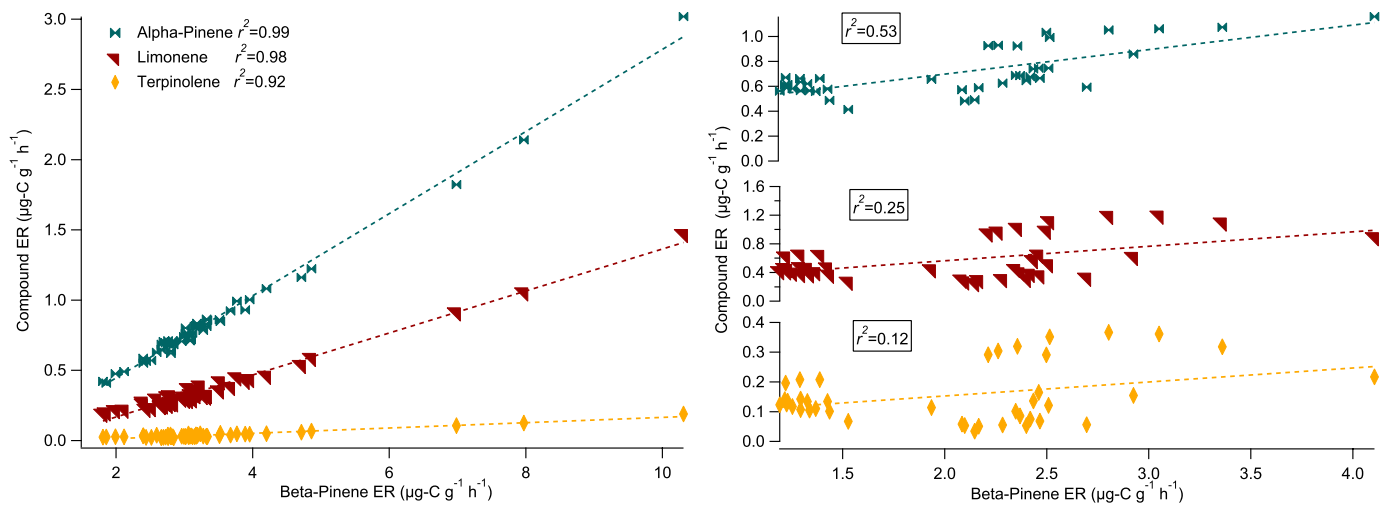

Figure 10. Scatterplots of the constitutive emissions alpha-pinene, limonene, and terpinolene vs. beta-pinene (the dominant constitutively emitted compound during the pre-treatment period) during experiment AG-E. Pre-treatment values are plotted on the left and post-treatment values are plotted on the right. Results of the linear regression analysis are included on the graphs.

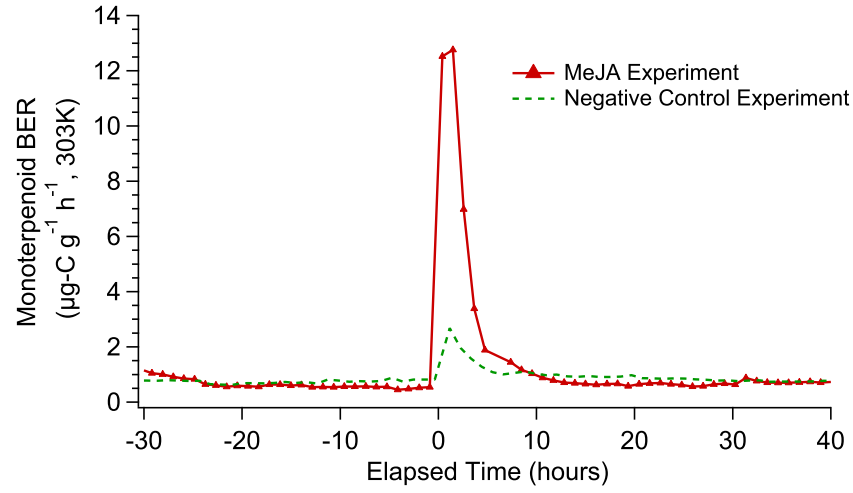

Figure 11. Results from two Pinus aristata experiments. Shown above is the time series of the sum monoterpenoid basal emission rates normalized to $303 \mathrm{~K}$ as a function of elapsed time since treatment application for the methyl jasmonate (MeJA) experiment (PAE) and the negative control experiment (PA-C).

The compounds that were most impacted by the stress treatment were highly variable between tree types. In the Thuja plicata experiment, the two monoterpenes that increased most were terpinolene and beta-myrcene. The emissions of these compounds increased by a combined $7.04 \mu \mathrm{g}$ $\mathrm{Cg}^{-1} \mathrm{~h}^{-1}$. This represents just over $80 \%$ of the total increase in monoterpene BER with terpinolene alone contributing to just over $60 \%$ of the total increase. The cymene isomers also exhibited a significant emission increase. The only other experiment where all three cymene isomers were measured was in the Pseudotsuga menziesii experiment. In this case, all cymene isomers increased, but to a lesser extent than during the Thuja plicata experiment. The most stress-enhanced compounds in the Pseudotsuga menziesii experiment were alpha-pinene, beta-pinene and 3-carene. 1,8-Cineol was identified as an important stress-enhanced or stress-stimulated compound in the Picea pungens and Abies grandis experiments but was never emitted from the

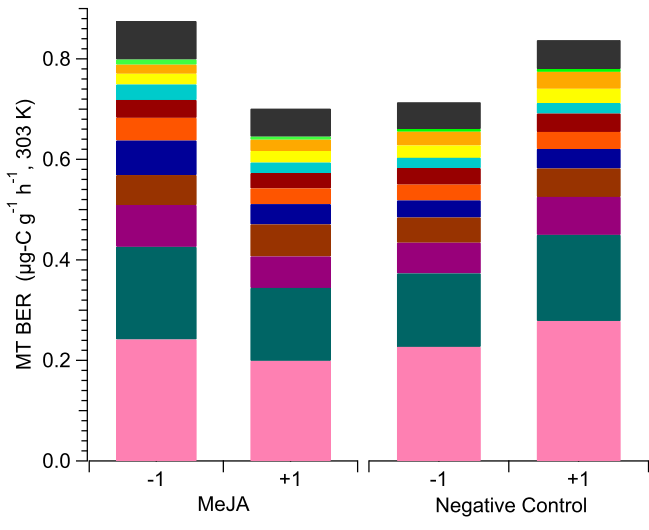

Figure 12. The Pinus aristata BVOC profile the day before treatment and the day after treatment for both the methyl jasmonate (MeJA) experiment (PA-E) and the negative control experiment (PA-C). The $x$ axis denotes the day relative to treatment application. The $y$ axis shows the monoterpenoid basal emission rate normalized to $303 \mathrm{~K}$. The left two bars illustrate the BVOC profiles from the methyl jasmonate (MeJA) experiment and the right two bars illustrate the BVOC profiles from the negative control experiment.

other two plant types. Beta-myrcene was an important stressenhanced compound for all plant types shown in the figure except for Pseudotsuga menziesii. Emissions of other compounds in our experiments generally either increased or stayed the same after treatment. An exception to this was in the Abies grandis experiment, where beta-pinene emissions significantly decreased after treatment.

Even though each experiment yielded fundamentally different results, several of the observed behaviors could be more broadly applicable. The differing results that were observed between the two Picea pungens MeJA experiments could indicate that plant stress susceptibility changes seasonally. Alternatively, if the Picea pungens plants had been exposed to an external unknown stressor for weeks prior to the 

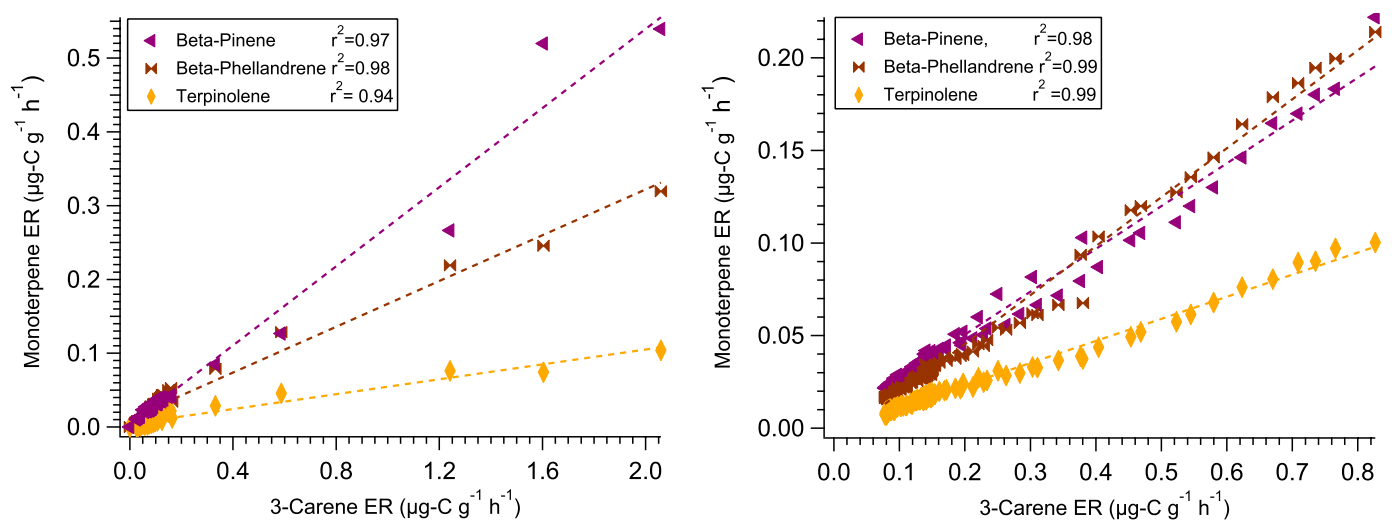

Figure 13. Scatterplots investigating the covariance between major constitutive emissions from Pinus aristata vs. 3-carene (the dominant constitutively emitted compound). Results from the linear regression fits of the data are summarized in the legends. The methyl jasmonate (MeJA) experiment is shown on the left and the negative control experiment is shown on the right.

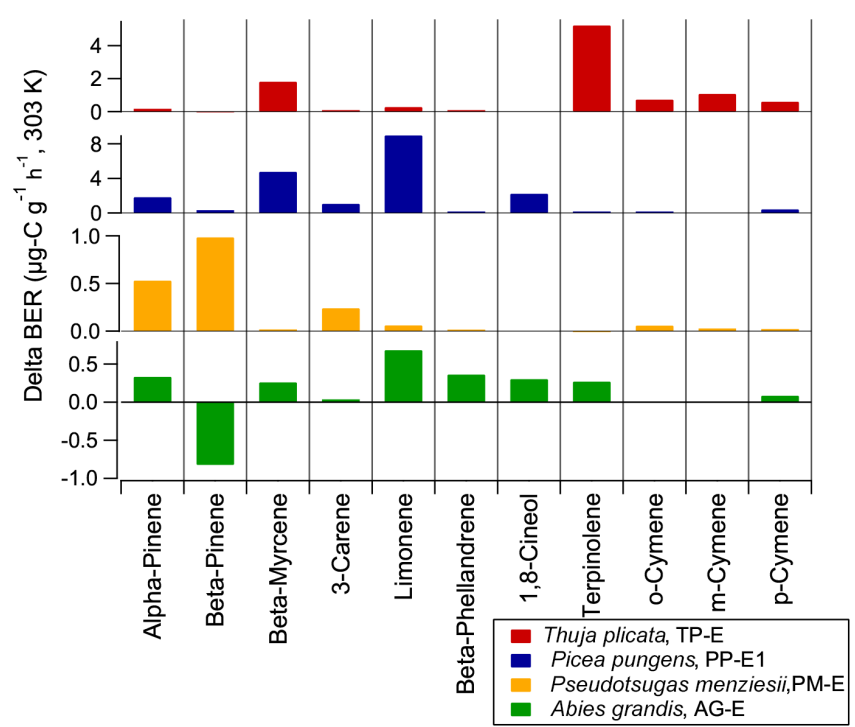

Figure 14. A summary of the change in basal emission rates after stress treatment application for some key compounds for each experiment where a stress response was observed.

second experiment (PP-E2), the results could indicate there is some breaking point where the plants simply do not respond to an additional stressor. These results would be in stark contrast to the Abies grandis stress response. The Abies grandis results suggest that despite the possible presence of an unknown stress prior to treatment, the simulated herbivory stress still caused additional changes to the emission profile. Thus, the presence of one stressor does not necessarily prevent a tree from responding to another stressor at the same time, and it is possible the effects of the two stressors could be additive. The response of the Thuja plicata emissions to the stress treatment can also provide valuable insight. Even though the pre-treatment emissions from the Thuja plicata plants were the lowest we measured from all the exper- iments, the post-treatment emission rates were substantial. This suggests that even naturally low-emitting species that would not contribute significantly to total forest BVOC flux under baseline conditions could be major sources of BVOC emissions under stressed conditions in a changing climate. Consequently, future surveys of BVOC emitters should not be limited to only the highest BVOC emitters in a region because this could change as global change stressors intensify. Finally, the near lack of any long-term response from Pinus aristata could indicate that some trees are more resistant to certain types of stress exposure than others. On the other hand, it is possible that, like Picea pungens, the Pinus aristata could demonstrate a completely different stress response depending on the season. The Pinus aristata experiments were conducted in May when pre-treatment emissions were low and the plants may have still been coming out of winter dormancy. This could have contributed to their apparent resistance to the treatment.

\subsection{Implications for BVOC atmospheric reactivity}

The MeJA stress treatment significantly changed the BVOC profile in many of the experiments. As discussed in the previous section, the specific compounds that were impacted by the treatment were highly variable between the different plant types. Consequently, the overall implications for atmospheric reactivity for the different plant types was also highly variable because different monoterpenoids have widely varying atmospheric reactivity (see Table 3 ). The pre- and posttreatment BVOC profile for each experiment was used to calculate the concentration-normalized $\mathrm{OH}$ and $\mathrm{O}_{3}$ reactivity by normalizing the relative contribution of each monoterpenoid to a sum monoterpenoid mixing ratio of $1 \mathrm{ppbV}$. The goal was to isolate the impact on reactivity due to changes in the BVOC profile only. Thus, the focus of this analysis was to investigate the change to the concentration-normalized oxidant reactivity value rather than the absolute pre- and post- 
Table 6. Summary of the BVOC pre-treatment (PreT) and post-treatment (PostT) concentration-normalized $\mathrm{OH}$ reactivity $(r \mathrm{OH})$ and concentration-normalized $\mathrm{O}_{3}$ reactivity $\left(r \mathrm{O}_{3}\right)$ at $298 \pm 2 \mathrm{~K}$. Reactivity values are presented in units of s ${ }^{-1}$. The $\sigma$ is the standard deviation of the averaged measurements. The percent difference between the pre-treatment and post-treatment values is also shown.

\begin{tabular}{|c|c|c|c|c|c|c|c|c|c|c|}
\hline Exp ID & PreT $r \mathrm{OH}$ & $\sigma$ & PostT $r \mathrm{OH}$ & $\sigma$ & $\%$ Diff & $\begin{array}{l}\text { PreT } r \mathrm{O}_{3} \\
\left(\times 10^{-6}\right)\end{array}$ & $\begin{array}{l}\sigma \\
\left(\times 10^{-6}\right)\end{array}$ & $\begin{array}{l}\text { PostT } r \mathrm{O}_{3} \\
\left(\times 10^{-6}\right)\end{array}$ & $\begin{array}{l}\sigma \\
\left(\times 10^{-6}\right)\end{array}$ & $\%$ Diff \\
\hline PP-E1 & 2.43 & 0.13 & 3.50 & 0.09 & 44.0 & 2.99 & 0.31 & 10.7 & 0.61 & 257.9 \\
\hline PP-C & 3.45 & 0.06 & 3.32 & 0.13 & -3.8 & 6.92 & 0.69 & 5.65 & 1.16 & -18.3 \\
\hline PP-E2 & 3.32 & 0.12 & 3.20 & 0.21 & -3.6 & 5.34 & 1.03 & 5.84 & 1.06 & 9.4 \\
\hline PA-E & 2.16 & 0.08 & 2.35 & 0.12 & 8.8 & 5.17 & 2.61 & 8.77 & 0.38 & 69.6 \\
\hline PA-C & 2.37 & 0.02 & 2.37 & 0.04 & 0.0 & 7.83 & 0.66 & 7.86 & 0.78 & 0.4 \\
\hline AG-E & 2.43 & 0.04 & 2.74 & 0.12 & 12.8 & 3.46 & 0.50 & 7.40 & 1.90 & 113.9 \\
\hline TP-E & 2.21 & 0.30 & 4.57 & 0.13 & 106.8 & 3.53 & 2.59 & 30.3 & 2.6 & 758.4 \\
\hline PM-E & 2.75 & 0.37 & 2.44 & 0.29 & -11.3 & 3.37 & 0.89 & 2.49 & 0.75 & -26.1 \\
\hline
\end{tabular}

treatment values; the reactivity results are presented in Table 6 .

For all experiments where a change in concentrationnormalized reactivity was observed, the $\mathrm{O}_{3}$ reactivity was more significantly affected than the $\mathrm{OH}$ reactivity. The three experiments that demonstrated the largest changes were TPE, PP-E1, and AG-E. For each of these experiments, the stress-induced changes to the BVOC profile increased both the $\mathrm{OH}$ and $\mathrm{O}_{3}$ concentration-normalized reactivity. The normalized $\mathrm{OH}$ reactivity of the Thuja plicata emission profile (TP-E) approximately doubled with an increase from 2.21 to $4.57 \mathrm{~s}^{-1}$ (106.8\% increase). This corresponds to a decrease in $\mathrm{OH}$ lifetime from 0.45 to $0.22 \mathrm{~s}$. The normalized $\mathrm{O}_{3}$ reactivity increased by nearly an order of magnitude from $3.53 \times 10^{-6} \mathrm{~s}^{-1}$ to $30.3 \times 10^{-6} \mathrm{~s}^{-1}$ (758.4\% increase). This corresponds to a decrease in $\mathrm{O}_{3}$ lifetime from 3.3 days to $9.2 \mathrm{~h}$. This is primarily due to the large increase in the relative amount of terpinolene, which has a high ozone reaction rate constant relative to most other monoterpenoids (Table 3 ). The normalized $\mathrm{OH}$ reactivity of the Picea pungens emission profile during the first experiment (PP-E1) increased from 2.43 to $3.50 \mathrm{~s}^{-1}$ (44\% increase). This corresponds to a decrease in the $\mathrm{OH}$ lifetime from 0.41 to $0.29 \mathrm{~s}$. The normalized $\mathrm{O}_{3}$ reactivity increased from $2.99 \times 10^{-6} \mathrm{~s}^{-1}$ to $10.7 \times 10^{-6} \mathrm{~s}^{-1}$ (257.9\% increase) corresponding to a decrease in $\mathrm{O}_{3}$ lifetime from 3.9 days to 1.1 days. The normalized $\mathrm{OH}$ reactivity of the Abies grandis emissions increased by a small amount from 2.43 to $2.74 \mathrm{~s}^{-1}$ ( $12.8 \%$ increase) corresponding to a decrease in $\mathrm{OH}$ lifetime from $0.41 \mathrm{~s}$ to $0.36 \mathrm{~s}$. However, the normalized $\mathrm{O}_{3}$ reactivity significantly increased from $3.46 \times 10^{-6} \mathrm{~s}^{-1}$ to $7.40 \times 10^{-6} \mathrm{~s}^{-1}(113.9 \%$ increase) corresponding to a decrease in $\mathrm{O}_{3}$ lifetime from 3.3 days to 1.6 days.

The Pinus aristata experiments (PA-C and PA-E) demonstrated very little change to the BVOC profile (see Sect. 3.6). For the negative control experiment (PA-C), the concentration-normalized reactivity results were consistent with no BVOC profile change; a $0 \%$ change was observed for $\mathrm{OH}$ reactivity and a $0.4 \%$ change was observed for $\mathrm{O}_{3}$ reactivity. The normalized $\mathrm{OH}$ reactivity increased slightly af- ter treatment during the PA-E experiment with an increase of $8.8 \%$. However, the PA-E normalized $\mathrm{O}_{3}$ reactivity increased significantly by $69.6 \%$ after MeJA treatment despite only minor changes to the BVOC profile (see Fig. 12). These results demonstrate that even small changes to the BVOC profile can have significant impacts on the overall atmospheric reactivity of the BVOC emissions.

Concentration-normalized reactivity of emissions from Pseudotsuga menziesii decreased slightly after treatment. The normalized $\mathrm{OH}$ reactivity decreased from 2.75 to $2.44 \mathrm{~s}^{-1}$ (decrease of $11.3 \%$ ) corresponding to a small increase in $\mathrm{OH}$ lifetime from 0.36 to $0.40 \mathrm{~s}$. The normalized $\mathrm{O}_{3}$ reactivity decreased from $3.37 \times 10^{-6} \mathrm{~s}^{-1}$ to $2.49 \times 10^{-6} \mathrm{~s}^{-1}$ (decrease of $26.1 \%$ ) corresponding to an increase in $\mathrm{O}_{3}$ lifetime from 3.4 days to 4.6 days. This was due to an increase in the relative amount of beta-pinene and 3carene emissions. Both of these compounds have reduced oxidant reactivity relative to other monoterpenoid compounds emitted in higher amounts prior to treatment (Table 3).

\section{Conclusions}

While many uncertainties remain regarding the impacts of herbivory stress on plant BVOC emissions, it is clear that plant responses are highly variable. Emissions of different compounds were impacted by the stress treatment for different tree types. The compounds that tended to be most affected by the stress treatment were alpha-pinene, betapinene, beta-myrcene, 3-carene, limonene, 1,8-cineol, terpinolene, and the cymene isomers. Aromatic cymenes sometimes contributed significantly to the emission profile pretreatment (i.e. Pseudotsuga menziesii), and often increased significantly post-treatment. These aromatic compounds are often not considered to be major precursors of biogenic SOA, but the emission rates observed in these experiments suggest they could be significant contributors to SOA formation in forests.

Four possible plant herbivory response patterns were observed in these experiments: (1) plant susceptibility to her- 
bivory stress changes seasonally; (2) after long-term exposure to one stressor, plant emissions decrease overall and do not respond to additional stressors; (3) alternatively, multiple stressors can be additive, perhaps if the second stressor is applied before the first stressor depletes terpene pools and initiates metabolic shutdown; and (4) herbivory stress could turn naturally low-emitting plants in a region to high emitters that would need to be considered in future climate scenarios with increased herbivory.

Stress-induced changes to the BVOC emission profile can result in significant changes to the concentration-normalized oxidant reactivity of plant emissions in the atmosphere. Increases in reactivity as high as $758.4 \%$ with $\mathrm{O}_{3}$ and $106.8 \%$ with $\mathrm{OH}$ were observed during the Thuja plicata experiment (TP-E). Furthermore, even small changes to the BVOC profile during the Pinus aristata MeJA experiment (PA-E) increased $\mathrm{O}_{3}$ reactivity by $69.6 \%$. These results highlight the importance of making quantitative, compound-specific BVOC emission rate measurements to understand the potential impact of stress-induced emissions on atmospheric chemistry. Changes in the oxidant reactivity of BVOC emissions have significant implications for the production of pollutants like ozone and secondary organic aerosol in forest environments.

Many questions still need to be addressed before stress impacts on BVOC emissions can be incorporated into emissions models. Future research needs to address the seasonality influence on plant susceptibility to herbivory stress. Additionally, the interaction between multiple stressors needs to be addressed because in the natural environment it is likely that plants are being exposed to multiple stressors more often than a single stressor in isolation. A broad survey of plant types should be used in these experiments to investigate which plants could become dominant BVOC emitters under future climate scenarios. Finally, all of these questions need to be asked regarding other types of plant stress including drought, thermal stress, ozone stress, and using different types of real herbivores and pathogens.

Acknowledgements. The authors thank Chuck Cody and the greenhouse staff for taking care of the plants used in this study. This work was supported by the US Department of Energy Early Career Research Program (award no. SC0003899).

Edited by: S. M. Noe

\section{References}

Achotegui-Castells, A., Llusia, J., Hódar, J. A., and Peñuelas, J.: Needle terpene concentrations and emissions of two coexisting subspecies of Scots pine attacked by the pine processionary moth (Thaumetopoea pityocampa), Acta Physiol. Plant., 35, 30473058, 2013.
Amin, H., Atkins, P. T., Russo, R. S., Brown, A. W., Sive, B., Hallar, A. G., and Huff Hartz K. E.: Effect of bark beetle infestation on secondary organic aerosol precursor emissions, Environ. Sci. Technol., 46, 5696-5703, 2012.

Amin, H., Russo, R. S. Sive, B. Hoebeke, E. R., Dodson, C., McCubbin, I. B. Hallar, A. G., and Huff Hartz, K. E.: Monoterpene emissions from bark beetle infested Engelmann spruce trees, Atmos. Environ., 72, 130-133, 2013.

Arneth, A. and Niinemets, Ü.: Induced BVOCs: how to bug our models?, Trends Plant Sci., 15, 118-125, 2010.

Atkinson, R.: Atmospheric chemistry of VOCs and NOx, Atmos. Environ., 34, 2063-2101, 2000.

Atkinson, R. and Arey, J.: Atmospheric Chemistry of Biogenic Organic Compounds, Accounts Chem. Res., 31, 574-583, doi:10.1021/ar970143z, 1998.

Atkinson, R., Hasegawa, D., and Aschmann, S. M.: Rate constants for the gas-phase reactions of $\mathrm{O}_{3}$ with a series of monoterpenes and related compounds at $296 \mathrm{~K}$, Int. J. Chem. Kinet., 22, 871887, 1990.

Bale, J. S., Masters, G. J., Hodkinson, I. D., Awmack, C., Bezemer, T. M., Brown, V. K., Butterfield, J., Buse, A., Coulson, J. C., Farrar, J., Good, J. E. G., Harrington, R., Hartley, S., Jones, T. H., Lindroth, R. L., Press, M. C., Symrnioudis, I., Watt, A. D., and Whittaker, J. B.: Herbivory in global climate change research: direct effects of rising temperature on insect herbivores, Glob. Change Biol., 8, 1-16, doi:10.1046/j.1365-2486.2002.00451.x, 2002.

Berg, A. R., Heald, C. L., Huff Hartz, K. E., Hallar, A. G., Meddens, A. J. H., Hicke, J. A., Lamarque, J.-F., and Tilmes, S.: The impact of bark beetle infestations on monoterpene emissions and secondary organic aerosol formation in western North America, Atmos. Chem. Phys., 13, 3149-3161, doi:10.5194/acp-13-31492013, 2013.

Blanch, J.-S., Peñuelas, J., Sardans, J., and Llusia, J.: Drought, warming and soil fertilization effects on leaf volatile terpene concentrations in Pinus halepensis and Quercus ilex, Acta Physiol. Plant., 31, 207-218, 2009.

Blande, J. D., Tiiva, P., Oksanen, E., and Holopainen, J. K.: Emission of herbivore-induced volatile terpenoids from two hybrid aspen (Populus tremula \& tremuloides) clones under ambient and elevated ozone concentrations in the field, Glob. Change Biol., 13, 2538-2550, doi:10.1111/j.1365-2486.2007.01453.x, 2007.

Brilli, F., Ciccioli, P., Frattoni, M., Prestininzi, M., Spanedda, A., and Loreto, F.: Constitutive and herbivore-induced monoterpenes emitted by Populus euroamericana leaves are key volatiles that orient Chrysomela populi beetles, Plant, Cell, \& Environment, 32, 542-552, 2009.

Bryan, A. M., Bertman, S. B., Carroll, M. A., Dusanter, S., Edwards, G. D., Forkel, R., Griffith, S., Guenther, A. B., Hansen, R. F., Helmig, D., Jobson, B. T., Keutsch, F. N., Lefer, B. L., Pressley, S. N., Shepson, P. B., Stevens, P. S., and Steiner, A. L.: Incanopy gas-phase chemistry during CABINEX 2009: sensitivity of a 1-D canopy model to vertical mixing and isoprene chemistry, Atmos. Chem. Phys., 12, 8829-8849, doi:10.5194/acp-12-88292012, 2012.

Bäck, J., P. Hari, Hakola, H. Juurola, E., and Kulmala, M.: Dynamics of monoterpene emissions in Pinus sylvestris during early spring, Boreal Environ. Res., 10, 409-424, 2005. 
Calfapietra, C., Fares, S., and Lofeto, F.: Volatile organic compounds from Italian vegetation and their interaction with ozone, Environ. Pollut., 157, 1478-1486, doi:10.1016/j.envpol.2008.09.048, 2009.

Calvert, J. G., Atkinson, R., Kerr, J. A., Madronich, S., Moortgat, G. K., Wallington, T. J., and Yarwood, G.: The mechanisms of atmospheric oxidation of the alkenes, Oxford University Press New York, available at: http://www.zohu.cn/viewarticle.php?id= 233404 (last acces: 13 June 2014), 2000.

Carslaw, K. S., Boucher, O., Spracklen, D. V., Mann, G. W., Rae, J. G. L., Woodward, S., and Kulmala, M.: A review of natural aerosol interactions and feedbacks within the Earth system, Atmos. Chem. Phys., 10, 1701-1737, doi:10.5194/acp-10-17012010, 2010.

Connor, E. C., Rott, A. S., Zeder, M., Jüttner, F., and Dorn, S.: ${ }^{13} \mathrm{C}$-labelling patterns of green leaf volatiles indicating different dynamics of precursors in Brassica leaves, Phytochemistry, 69, 1304-1312, 2008.

Constable, J. V. H., Litvak, M. E., Greenberg, J. P., and Monson, R. $\mathrm{K}$ : Monoterpene emission from coniferous trees in response to elevated $\mathrm{CO}_{2}$ concentration and climate warming, Glob. Change Biol., 5, 252-267, doi:10.1046/j.1365-2486.1999.00212.x, 1999.

Copolovici, L., Kaennaste, A., Remmel, T., Vislap, V., and Niinemets, U.: Volatile Emissions from Alnus glutionosa Induced by Herbivory are Quantitatively Related to the Extent of Damage, J. Chem. Ecol., 37, 18-28, doi:10.1007/s10886-010-9897-9, 2011.

Corchnoy, S. B. and Atkinson, R.: Kinetics of the gas-phase reactions of hydroxyl and nitrogen oxide (NO3) radicals with 2carene, 1, 8-cineole, p-cymene, and terpinolene, Environ. Sci. Technol., 24, 1497-1502, 1990.

Dudareva, N., Negre, F., Nagegowda, D. A., and Orlova, I.: Plant volatiles: recent advances and future perspectives, Crit. Rev. Plant Sci., 25, 417-440, 2006.

Ehn, M., Thornton, J. A., Kleist, E., Sipilä, M., Junninen, H., Pullinen, I., Springer, M., Rubach, F., Tillmann, R., and Lee, B.: A large source of low-volatility secondary organic aerosol, Nature, 506, 476-479, 2014.

Engelberth, J., Alborn, H. T., Schmelz, E. A., and Tumlinson, J. H.: Airborne signals prime plants against insect herbivore attack, $\mathrm{P}$. Natl. Acad. Sci. USA, 101, 1781-1785, 2004.

Faiola, C. L., Erickson, M. H., Fricaud, V. L., Jobson, B. T., and VanReken, T. M.: Quantification of biogenic volatile organic compounds with a flame ionization detector using the effective carbon number concept, Atmos. Meas. Tech., 5, 1911-1923, doi:10.5194/amt-5-1911-2012, 2012.

Faiola, C. L., VanderSchelden, G. S., Wen, M., Elloy, F. C., Cobos, D. R., Watts, R. J., Jobson, B. T., and VanReken, T. M.: SOA Formation Potential of Emissions from Soil and Leaf Litter, Environ. Sci. Technol., 48, 938-946, doi:10.1021/es4040045, 2014a.

Faiola, C. L., Wen, M., and VanReken, T. M.: Chemical characterization of biogenic SOA generated from plant emissions under baseline and stressed conditions: inter- and intra-species variability for six coniferous species, Atmos. Chem. Phys. Discuss., 14, 25167-25212, doi:10.5194/acpd-14-25167-2014, 2014b.

Fall, R. and Monson, R. K.: Isoprene emission rate and intercellular isoprene concentration as influenced by stomatal distribution and conductance, Plant Physiol., 100, 987-992, 1992.
Farmer, E. E. and Ryan, C. A.: Interplant communication: Airborne methyl jasmonate induces synthesis of proteinase inhibitors in plant leaves, P. Natl. Acad. Sci. USA, 87, 7713-7716, 1990.

Filella, I., Peñuelas, J., and Llusia, J.: Dynamics of the enhanced emissions of monoterpenes and methyl salicylate, and decreased uptake of formaldehyde, by Quercus ilex leaves after application of jasmonic acid, New Phytol., 169, 135-144, doi:10.1111/j.1469-8137.2005.01570.x, 2006.

Filella, I., Wilkinson, M. J., Llusia, J., Hewitt, C. N., and Peñuelas, J.: Volatile organic compounds emissions in Norway spruce (Picea abies) in response to temperature changes, Physiol. Plant., 130, 58-66, doi:10.1111/j.1399-3054.2007.00881.x, 2007.

Gai, Y., Wang, W., Ge, M., Kjaergaard, H. G., Jørgensen, S., and $\mathrm{Du}, \mathrm{L} .:$ Methyl chavicol reactions with ozone, $\mathrm{OH}$ and $\mathrm{NO}_{3}$ radicals: Rate constants and gas-phase products, Atmos. Environ., 77, 696-702, 2013.

Geron, C., Rasmussen, R., R Arnts, R., and Guenther, A.: A review and synthesis of monoterpene speciation from forests in the United States, Atmos. Environ., 34, 1761-1781, 2000.

Graus, M., Eller, A. S. D., Fall, R., Yuan, B., Qian, Y., Westra, P., de Gouw, J., and Warneke, C.: Biosphere-atmosphere exchange of volatile organic compounds over $\mathrm{C} 4$ biofuel crops, Atmos. Environ., 66, 161-168, doi:10.1016/j.atmosenv.2011.12.042, 2013.

Greenberg, J. P., Asensio, D., Turnipseed, A., Guenther, A. B., Karl, T., and Gochis, D.: Contribution of leaf and needle litter to whole ecosystem BVOC fluxes, Atmos. Environ., 59, 302-311, doi:10.1016/j.atmosenv.2012.04.038, 2012.

Griffin, R. J., Cocker, D. R., Flagan, R. C., and Seinfeld, J. H.: Organic aerosol formation from the oxidation of biogenic hydrocarbons, J. Geophys. Res.-Atmosp., 104, 3555-3567, doi:10.1029/1998JD100049, 1999.

Guenther, A. B., Zimmerman, P. R., Harley, P. C., Monson, R. K., and Fall, R.: Isoprene and monoterpene emission rate variability: model evaluations and sensitivity analyses, J. Geophys. Res.Atmospheres (1984-2012), 98, 12609-12617, 1993.

Guenther, A., Geron, C., Pierce, T., Lamb, B., Harley, P., and Fall, R.: Natural emissions of non-methane volatile organic compounds, carbon monoxide, and oxides of nitrogen from North America, Atmos. Environ., 34, 2205-2230, 2000.

Guenther, A. B., Jiang, X., Heald, C. L., Sakulyanontvittaya, T., Duhl, T., Emmons, L. K., and Wang, X.: The Model of Emissions of Gases and Aerosols from Nature version 2.1 (MEGAN2.1): an extended and updated framework for modeling biogenic emissions, Geosci. Model Dev., 5, 1471-1492, doi:10.5194/gmd-51471-2012, 2012.

Hamilton, J. F., Lewis, A. C., Carey, T. J., Wenger, J. C., Borrás i Garcia, E., and Muñoz, A.: Reactive oxidation products promote secondary organic aerosol formation from green leaf volatiles, Atmos. Chem. Phys., 9, 3815-3823, doi:10.5194/acp-9-38152009, 2009.

Harley, P., Deem, G., Flint, S., and Caldwell, M.: Effects of growth under elevated UV-B on photosynthesis and isoprene emission in Quercus gambelii and Mucuna pruriens, Glob. Change Biol., 2, 149-154, 1996.

Heiden, A. C., Hoffmann, T., Kahl, J., Kley, D., Klockow, D., Langebartels, C., Mehlhorn, H., Sandermann Jr, H., Schraudner, M., Schuh, G., and others: Emission of volatile signal and defense molecules from ozone-exposed plants, Ecol. Appl., 9, 1160-1167, 1999. 
Helmig, D., Daly, R. W., Milford, J., and Guenther, A.: Seasonal trends of biogenic terpene emissions, Chemosphere, 93, 35-46, doi:10.1016/j.chemosphere.2013.04.058, 2013.

Herrmann, K. M. and Weaver, L. M.: The Shikimate Pathway, Annu. Rev. Plant. Phys., 50, 473-503, doi:10.1146/annurev.arplant.50.1.473, 1999.

Holopainen, J. K. and Gershenzon, J.: Multiple stress factors and the emission of plant VOCs, Trends Plant Sci., 15, 176-184, 2010.

Hu, Z., Shen, Y., Luo, Y., Shen, F., Gao, H., and Gao, R.: Aldehyde volatiles emitted in succession from mechanically damaged leaves of poplar cuttings, J. Plant Biol., 51, 269-275, 2008.

Jansen, R. M. C., Hofstee, J. W., Wildt, J., Verstappen, F. W. A., Bouwmeester, H. J., Posthumus, M. A., and van Henten, E. J.: Health monitoring of plants by their emitted volatiles: trichome damage and cell membrane damage are detectable at greenhouse scale, Ann. Appl. Biol., 154, 441-452, doi:10.1111/j.17447348.2008.00311.x, 2009a.

Jansen, R. M. C., Miebach, M., Kleist, E., van Henten, E. J., and Wildt, J.: Release of lipoxygenase products and monoterpenes by tomato plants as an indicator of Botrytis cinereainduced stress, Plant Biol., 11, 859-868, doi:10.1111/j.14388677.2008.00183.x, 2009b.

Kesselmeier, J. and Staudt, M.: Biogenic volatile organic compounds (VOC): an overview on emission, physiology and ecology, J. Atmos. Chem., 33, 23-88, 1999.

Kleist, E., Mentel, T. F., Andres, S., Bohne, A., Folkers, A., Kiendler-Scharr, A., Rudich, Y., Springer, M., Tillmann, R., and Wildt, J.: Irreversible impacts of heat on the emissions of monoterpenes, sesquiterpenes, phenolic BVOC and green leaf volatiles from several tree species, Biogeosciences, 9, 51115123, doi:10.5194/bg-9-5111-2012, 2012.

Kroll, J. H. and Seinfeld, J. H.: Chemistry of secondary organic aerosol: Formation and evolution of low-volatility organics in the atmosphere, Atmos. Environ., 42, 3593-3624, doi:10.1016/j.atmosenv.2008.01.003, 2008.

Laothawornkitkul, J., Moore, J. P., Taylor, J. E., Possell, M., Gibson, T. D., Hewitt, C. N., and Paul, N. D.: Discrimination of Plant Volatile Signatures by an Electronic Nose: A Potential Technology for Plant Pest and Disease Monitoring, Environ. Sci. Technol., 42, 8433-8439, doi:10.1021/es801738s, 2008.

Loreto, F. and Delfine, S.: Emission of isoprene from salt-stressed Eucalyptus globulus leaves, Plant Physiol., 123, 1605-1610, 2000.

Loreto, F. and Schnitzler, J.-P.: Abiotic stresses and induced BVOCs, Trends Plant Sci., 15, 154-166, 2010.

Loreto, F., Ciccioli, P., Cecinato, A., Brancaleoni, E., Frattoni, M., and Tricoli, D.: Influence of environmental factors and air composition on the emission of $\alpha$-Pinene from Quercus ilex leaves, Plant Physiol., 110, 267-275, 1996.

Loreto, F., Nascetti, P., Graverini, A., and Mannozzi, M.: Emission and content of monoterpenes in intact and wounded needles of the Mediterranean pine, Pinus pinea, Funct. Ecol., 14, 589-595, 2000.

Maffei, M. E.: Sites of synthesis, biochemistry and functional role of plant volatiles, S. Afr. J. Bot., 76, 612-631, 2010.

Martin, D. M., Gershenzon, J., and Bohlmann, J.: Induction of volatile terpene biosynthesis and diurnal emission by methyl jasmonate in foliage of Norway spruce, Plant Physiol., 132, 15861599, 2003.
Mentel, Th. F., Kleist, E., Andres, S., Dal Maso, M., Hohaus, T., Kiendler-Scharr, A., Rudich, Y., Springer, M., Tillmann, R., Uerlings, R., Wahner, A., and Wildt, J.: Secondary aerosol formation from stress-induced biogenic emissions and possible climate feedbacks, Atmos. Chem. Phys., 13, 8755-8770, doi:10.5194/acp-13-8755-2013, 2013.

Niinemets, Ü.: Mild vs. severe stress and BVOCs: thresholds, priming and consequences, Trends Plant Sci., 15, 145-153, doi:10.1016/j.tplants.2009.11.008, 2010.

Niinemets, Ü., Loreto, F., and Reichstein, M.: Physiological and physicochemical controls on foliar volatile organic compound emissions, Trends Plant Sci., 9, 180-186, 2004.

Niinemets, Ü., Arneth, A., Kuhn, U., Monson, R. K., Peñuelas, J., and Staudt, M.: The emission factor of volatile isoprenoids: stress, acclimation, and developmental responses, Biogeosciences, 7, 2203-2223, doi:10.5194/bg-7-2203-2010, 2010.

Nölscher, A. C., Williams, J., Sinha, V., Custer, T., Song, W., Johnson, A. M., Axinte, R., Bozem, H., Fischer, H., Pouvesle, N., Phillips, G., Crowley, J. N., Rantala, P., Rinne, J., Kulmala, M., Gonzales, D., Valverde-Canossa, J., Vogel, A., Hoffmann, T., Ouwersloot, H. G., Vilà-Guerau de Arellano, J., and Lelieveld, J.: Summertime total $\mathrm{OH}$ reactivity measurements from boreal forest during HUMPPA-COPEC 2010, Atmos. Chem. Phys., 12, 8257-8270, doi:10.5194/acp-12-8257-2012, 2012.

Ormeno, E., Fernandez, C., and Mévy, J.-P.: Plant coexistence alters terpene emission and content of Mediterranean species, Phytochemistry, 68, 840-852, 2007.

Ortega, J., Helmig, D., Daly, R. W., Tanner, D. M., Guenther, A. B., and Herrick, J. D.: Approaches for quantifying reactive and low-volatility biogenic organic compound emissions by vegetation enclosure techniques - part B: applications, Chemosphere, 72, 365-380, doi:10.1016/j.chemosphere.2008.02.054, 2008.

Peñuelas, J. and Staudt, M.: BVOCs and global change, Trends Plant Sci., 15, 133-144, doi:10.1016/j.tplants.2009.12.005, 2010.

Priemé, A., Knudsen, T. B., Glasius, M., and Christensen, S.: Herbivory by the weevil, Strophosoma melanogrammum causes severalfold increase in emission of monoterpenes from young Norway spruce (Picea abies) Atmos. Environ., 34, 711-718, 2000.

Reissell, A., Arey, J., and Atkinson, R.: Atmospheric chemistry of camphor, Int. J. Chem. Kinet., 33, 56-63, 2001.

Rodriguez-Saona, C., Crafts-Brandner, S. J., Pare, P. W., and Henneberry, T. J.: Exogenous methyl jasmonate induces volatile emissions in cotton plants, J. Chem. Ecol., 27, 679-695, 2001.

Semiz, G., Blande, J. D., Heijari, J., Işık, K., Niinemets, Ü., and Holopainen, J. K.: Manipulation of VOC emissions with methyl jasmonate and carrageenan in the evergreen conifer Pinus sylvestris and evergreen broadleaf Quercus ilex, Plant Biol., 14, 57-65, 2012.

Simpraga, M., Verbeeck, H., Demarcke, M., Joo, E., Pokorska, O., Amelynck, C., Schoon, N., Dewulf, J., Van Langenhove, H., Heinesch, B., Aubinet, M., Laffineur, Q., Muller, J.-F., and Steppe, K.: Clear link between drought stress, photosynthesis and biogenic volatile organic compounds in Fagus sylvatica L., Atmos. Environ., 45, 5254-5259, doi:10.1016/j.atmosenv.2011.06.075, 2011.

Staudt, M. and Lhoutellier, L.: Volatile organic compound emission from holm oak infested by gypsy moth larvae: evidence for dis- 
tinct responses in damaged and undamaged leaves, Tree Physiol., 27, 1433-1440, 2007.

Sternberg, J. C., Gallaway, W. S., and Jones, D. T. L.: Chapter XVIII: The Mechanism of Response of Flame Ionization Detectors, in: Gas Chromatography: Third International Symposium Held Under the Auspices of the Analysis Instrumentation Division of the Instrument Society of America, edited by: Brenner, N., Callen, J. E., and Weiss, M. D., Academic Press, New York and London, 231-267, 1962.

Teuber, M., Zimmer, I., Kreuzwieser, J., Ache, P., Polle, A., Rennenberg, H., and Schnitzler, J.-P.: VOC emissions of Grey poplar leaves as affected by salt stress and different $\mathrm{N}$ sources, Plant Biol., 10, 86-96, doi:10.1111/j.1438-8677.2007.00015.x, 2008.

Toome, M., Randjarv, P., Copolovici, L., Niinemets, U., Heinsoo, K., Luik, A., and Noe, S. M.: Leaf rust induced volatile organic compounds signalling in willow during the infection, Planta, 232, 235-243, doi:10.1007/s00425-010-1169-y, 2010.

Trowbridge, A. M., Daly, R. W., Helmig, D., Stoy, P. C., and Monson, R. K. : Herbivory and climate interact serially to control monoterpene emissions from pinyon pine forests, Ecology, 95, 1591-1603, 2014.

United States Environmental Protection Agency: Estimation Programs Interface Suite ${ }^{\mathrm{TM}}$ for Microsoft ${ }^{\circledR}$ Windows, v 4.11, US EPA, Washington, DC, USA, available at: http://www.epa. gov/opptintr/exposure/pubs/episuite.htm (last access: 24 January 2015), 2014.
Vuorinen, T., Nerg, A. M., and Holopainen, J. K.: Ozone exposure triggers the emission of herbivore-induced plant volatiles, but does not disturb tritrophic signalling, Environ. Pollut., 131, 305-311, doi:10.1016/j.envpol.2004.02.027, 2004.

Vuorinen, T., Nerg, A.-M., Syrjala, L., Peltonen, P., and Holopainen, J. K.: Epirrita autumnata induced VOC emission of silver birch differ from emission induced by leaf fungal pathogen, Arthropod-Plant Interact., 1, 159-165, doi:10.1007/s11829-007-9013-4, 2007.

Warneke, C., Karl, T., Judmaier, H., Hansel, A., Jordan, A., Lindinger, W., and Crutzen, P. J.: Acetone, methanol, and other partially oxidized volatile organic emissions from dead plant matter by abiological processes: Significance for atmospheric HOx chemistry, Global Biogeochem. Cy., 13, 9-17, 1999.

Winter, T. R., Borkowski, L., Zeier, J., and Rostas, M.: Heavy metal stress can prime for herbivore-induced plant volatile emission, Plant Cell Environ., 35, 1287-1298, doi:10.1111/j.13653040.2012.02489.x, 2012. 